Portland State University

PDXScholar

1981

\title{
An Alumni survey of the School of Social Work, Portland State University
}

\author{
Stephen R. Fishack \\ Portland State University \\ Robert A. Forlenza \\ Portland State University \\ Susan D. Fredd \\ Portland State University \\ Gigi Gandy \\ Portland State University \\ William P. Goldsmith \\ Portland State University
}

See next page for additional authors

Follow this and additional works at: https://pdxscholar.library.pdx.edu/open_access_etds

Part of the Higher Education Commons, and the Social Work Commons

Let us know how access to this document benefits you.

\section{Recommended Citation}

Fishack, Stephen R.; Forlenza, Robert A.; Fredd, Susan D.; Gandy, Gigi; Goldsmith, William P.; Grier, Thomas L.; and Lehto, Sheila K., "An Alumni survey of the School of Social Work, Portland State University" (1981). Dissertations and Theses. Paper 3448.

https://doi.org/10.15760/etd.5332

This Thesis is brought to you for free and open access. It has been accepted for inclusion in Dissertations and Theses by an authorized administrator of PDXScholar. Please contact us if we can make this document more accessible: pdxscholar@pdx.edu. 


\section{Author}

Stephen R. Fishack, Robert A. Forlenza, Susan D. Fredd, Gigi Gandy, William P. Goldsmith, Thomas L. Grier, and Sheila K. Lehto 
AN ALUMNI SURVEY OF

THE SCHOOL OF SOCIAL WORK,

PORTLAND STATE UNIVERSITY

\section{by}

Stephen R. Fishack

Robert A. Forlenza

Susan D. Fredd

Gigi (Gail) Gandy

William P. Goldsmith

Thomas L. Grier

Sheila K. Lehto

A research practicum submitted in partial fulfillment of the requirements for the degree of

MASTER OF SOCIAL WORK

Portland State University 1981 
Acknowledgements

We wish to extend thanks to Dr. Robert Holloway for his assistance throughout this project. His knowledge contributed greatly to the feasibility of this research practicum.

Thanks also are due to Tane Hunter (for her invaluable contribution compiling a mailing list) and to the Class of 1968 Alumni Fund (for their financial contribution). 
TO THE OFFICE OF GRADUATE STUDIES AND RESEARCH:

The Advisor approves the practicum presented June 1, 1981.

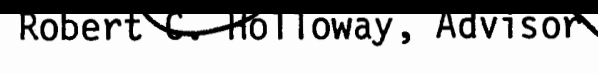




\section{TABLE OF CONTENTS}

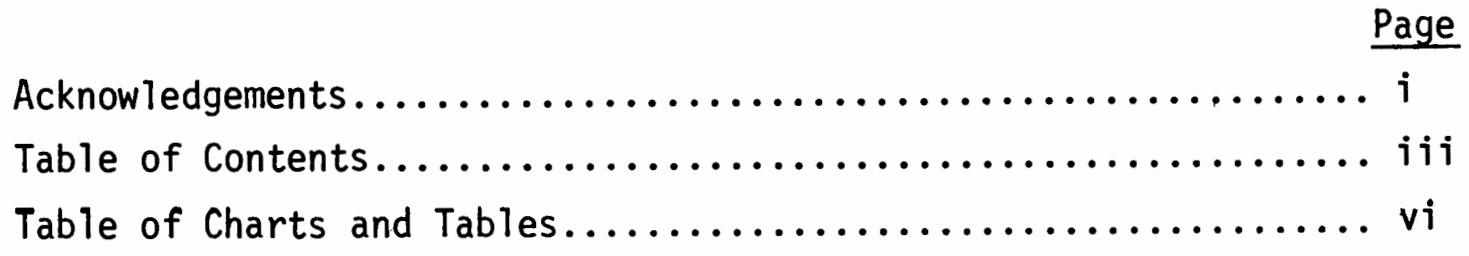

I. Introduction to the Survey
A. Problem Statement......................... 1
B. Literature Review........................... 3
C. Methodology............................ 7
D. Analysis of Results........................ 10
E. Summary.............................. 17

II. Description of Alumni Social Work Activities
A. Problem Statement.......................... 19

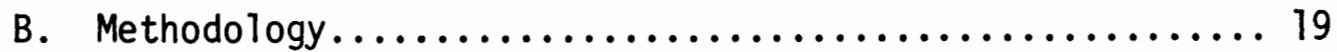
C. Analysis of Results........................ 20

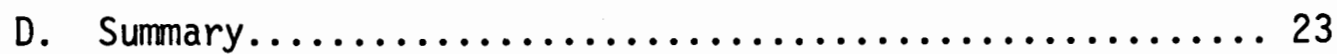

III. Alumni Evaluation of School of Social Work Curriculum
A. Problem Statement............................ 24

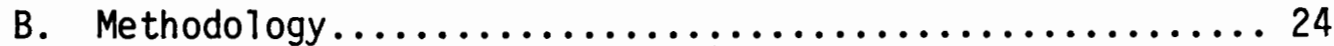

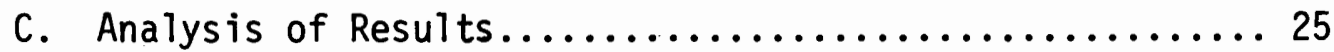
D. Summary and Recommendations.......................... 31

IV. Assessment of Direct Service Alumni Intervention Techniques

A. Problem Statement......................... 32

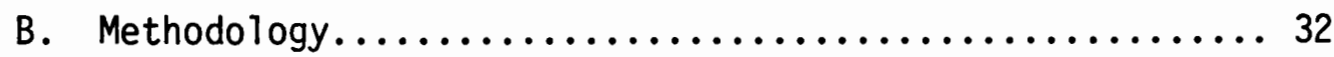

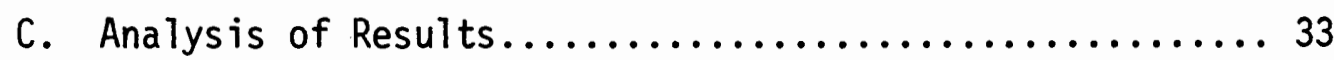

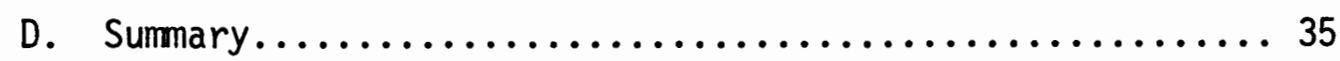


$\underline{\text { Page }}$

V. The Relationship Between Program Track and Career Success

A. Problem Statement.......................... 37

B. Literature Review and Methodology............... 38

C. Analysis of Results........................ 40

D. Summary and Recommendations $\ldots \ldots \ldots \ldots \ldots \ldots \ldots \ldots, 46$

VI. Alumni Awareness of Discrimination in Hiring, Service Delivery and Personal Experience

A. Problem Statement.......................... 49

B. Literature Review......................... 50

C. Methodology.................................. 51

D. Analysis of Results........................ 52

E. Summary and Recommendations.................. 55

VII. Minority Prejudice as it Relates to Alumni Social Work Practice

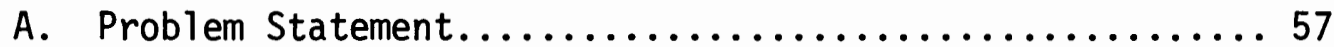

B. Literature Review......................... 57

C. Methodology.............................. 59

D. Analysis of Results........................61 61

E. Summary and Recommendations................... 64

VIII. Assessment of Alumni Burn-Out in Social Work Practice

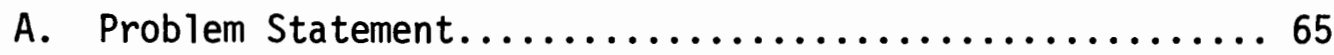

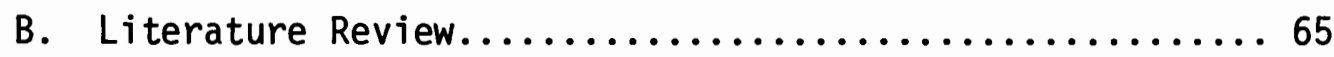

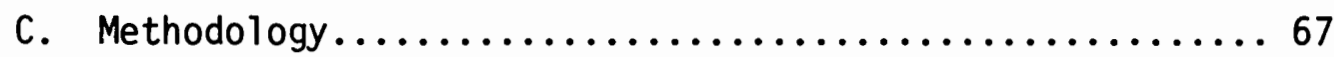

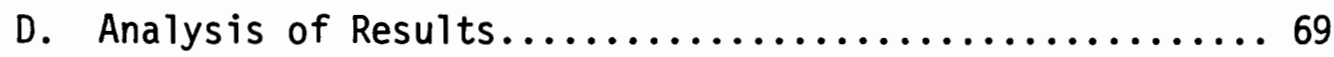

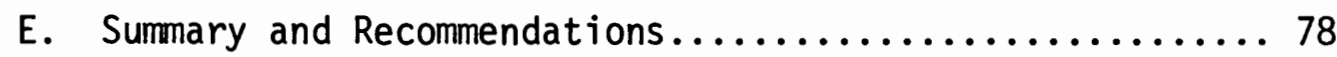

IX. Assessment of Alumni Social Welfare Policy Attitudes

A. Problem Statement and Literature Review............ 81

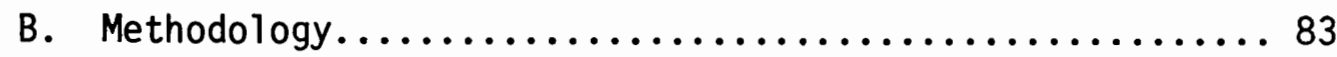

C. Analys is of Results.......................... 84

D. Summary and Recommendations....................... 91

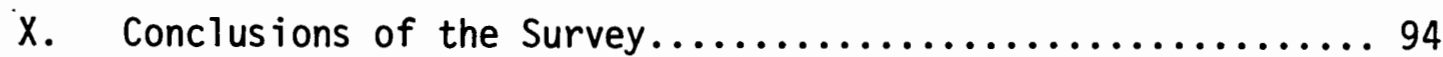


XI. Bibliography.

XII. Appendix

The Questionnaire........................... 100 


\section{TABLE OF TABLES AND CHARTS}

Page

Table II-A Social Work Activities Ranked by Summation Values................................ 22

Table III-A Courses Ranked for Helpfulness by Summation Value and Average Score................... 27

Table III-B Most Helpful and Least Helpful Courses........ 29

Table III-C Why Most Helpful; why Least Helpful.......... 30

Table III-D Courses Suggested as Additions to Curriculum.... 31

Table IV-A Intervention Technique Ranked According to Summation Value....................... 34

Table IV-B Intervention Techniques Deserving Additional Emphasis...................... 36

Table V-A

Percentage of Alumni in Supervisory or Managerial Positions by Program Track......... 41

Chart V-A Percentage of Alumni in Supervisory-Management Positions by Year of Degree................ 42

Chart V-B Job Activities Occupying the Most Time by Program Track.

Table V-B Percentage of MSW Graduates With Successful Careers Compared by Program Track........... 46

Table VII-A Prejudice in Social Work Practice............ 62

Table VIII-A Totempth and Age......................... 72

Table VIII-B Totburn and Number of Hours Worked Per Week.... 75

Table VIII-C Totburn and Job Setting................. 77

Table VIII-D Totempth and Job Setting................. 79

Table IX-A Distribution of Item Response............ 85 


\section{Introduction to the Survey}

\section{A. PROBLEM STATEMENT}

The alumni survey conducted at Portland State University School of Social Work by second year students had two purposes. One purpose was to fulfill the research practicum requirements of a Masters of Social Work degree by providing experience in the area of applied survey research. The other was to provide a data base for future alumni research at the school.

Selltiz, et al., in their book, Research Methods in Social Relations, ask the question, "Why is it important to be familiar with the research process?" They answer with the following statements: "Research techniques are the tools of the trade.... The student needs not only to develop skill in using them but also to understand the logic behind them." Further, "The positions for which social science students are likely to be preparing themselves...--community consultation, social work--increasingly call for the ability to evaluate and to use research results: to judge whether a study was carried out in such a way that one can have reasonable confidence in its findings and whether its findings are applicable to the specific situation at hand" (1976, p. 11).

While published research may strongly suggest the existence of a prescribed sequence of procedures, each step presupposing the completion of the preceding one, Selltiz, et al. suggest the actual research process almost never follows the neat sequential pattern of activities suggested in the organization of research reports and the many additional activities rarely mentioned in the published studies (1976, p. 13).

This survey, the process of its creation, the collection and 
interpretation of data and this group's ultimate findings, has provided the practical experience needed by the MSW student in the planning and implementation of a research project.

Because the needs of individuals and communities served by social workers are continually changing, and because these changes require a response on the part of social work educators, our survey has focused on the school's curriculum and its effectiveness in preparing the MSW graduates of P.S.U. School of Social Work in the last ten years. The findings of this survey will be presented formally to the school's curriculum committee, which has expressed considerable interest in the survey .

Students in this research practicum hope to provide specific information to the school regarding the effectiveness of course content, learning format and the practical and theoretical education received by P.S.U. MSW graduates of the last ten years. In addition, individual students have pursued, within the general format, specific areas of personal interest such as issues related to "burn-out," prejudicial or discriminatory attitudes, and methods used in the practice of social work. The research attempts to describe such areas as: the social work setting, activities, salaries, and levels of job satisfaction experienced by P.S.U. graduates as professional social workers. In other words, what can the P.S.U. MSW graduate expect to encounter in the real world versus the theoretical world of the student? Do graduates possess the skills and knowledge required to fulfill the expectations held by society and the profession of social workers?

A good feedback system insures a continual adjustment between needs 
providers and actual needs. It is the hope of this research group to provide just that feedback in order to assist the P.S.U. School of Social Work in adjusting its curriculum to meet the present needs of the community and students it serves. As an additional outcome, this group will provide a data base upon which future alumni surveys may be based. The remainder of this section reports on the survey as a whole. Subsequent sections report on specific areas of interest explored by individual group members. In essence, specific research questions were pursued individually within the structure of the overall survey.

\section{B. LITERATURE REVIEW}

The student who fully understands the logic and skills of survey research will be excellently equipped to learn and to use other social research methods (Babbie, 1973, p. 45).

There are three general classifications of social science research: exploratory, descriptive and experimental. The alumni survey is a questionnaire, which is defined as descriptive research. There are common characteristics of descriptive research which make it different from exploratory or experimental.

The questions used in descriptive study presuppose more prior knowledge than questions posed for exploratory research. Descriptive studies define clearly what is to be measured and how the objectives are measured. Additionally, the "given population" or "given community" is clearly specified. As Selltiz, et al. purport, "In collecting evidence for a study of this sort, what is needed is not so much flexibility as a clear formulation of what and who is to be measured and 
techniques for valid and reliable measurements" (1976, p. 102).

Descriptive research is concerned with describing the characteristics of communities; e.g., age distribution, racial background and income levels. This kind of study explores a specified population that holds certain views or attitudes. Descriptive research is also concerned with discovering or testing whether certain variables are associated. Specifically, the alumni survey is collecting data from people who have obtained MSW's from Portland State University in the last ten years. The survey is asking both factual questions and questions aimed at discerning attitudes, values and beliefs. The survey also reviews demographic data, such as age distribution, race and sex. "None of these questions, as they have been presented, involves a hypothesis that one of the variables leads to or produces the other; questions embodying such hypotheses pose different requirements for research procedures" (p. 102).

Gaining accurate and complete information are considerations throughout descriptive research. These factors affect all facets of the study, including the selection of the sample, methods of data collection and analyzing the data. For example, when using questionnaires as a means of data collection, the investigators are relying on self-report from the respondents; the investigators do not observe the actual behavior or attitudes. The questions may also ask the respondent to recall past events or feelings, thereby relying on memory. "Thus the investigator can ordinarily obtain only material that the subject is willing and able to report" (p. 292).

There are several advantages for using a survey as a means of data collection rather than another common method, the interview. The survey 
format requires much less time and skill to administer; therefore is less costly. The questionnaire or survey can be mailed simultaneously to large numbers of people, whereas interviews are usually individually administered.

When answering a written questionnaire, respondents may feel more confident in their anonymity and therefore more likely to express their opinions, viewpoints and beliefs. "If a questionnaire is presented as anonymous and there is no apparent identifying information, the respondents may feel greater confidence that their replies will not (or cannot) be identified as coming from them" (p. 295).

In choosing the mailed questionnaire as a means of data collection for the alumni survey, disadvantages were also considered. Return rates for questionnaires are lower than for personal or telephone interviews. Return rates usually vary from ten to fifty percent. However, several factors affect the actual return rate. These include the visual attractiveness of the questionnaire, clarity and precision of the questions, the length of the questionnaire, and the degree of interest of the questions to the person responding. Special attention and consideration were given to these issues when designing the alumni survey.

A personal or telephone interview is more immediately sensitive than the questionnaire. If a misunderstanding of terms occurs, the interviewer may respond with corrective feedback. This mechanism highlights the importance of carefully operationalizing the terms and definitions as used in the questionnaire. "In a questionnaire, if the subject misinterprets a question or records his or her responses in a baffling manner, there is usually little that can be done to remedy the situation" (p. 297). 
The information gleaned from the alumni survey is from the questions developed. Therefore, both question content and structure are extremely important elements to consider. These elements affect the accuracy of the data collected. Many questions on the alumni survey are designed to obtain factual information, e.g., age, marital status, income and gender. Research has indicated that degrees of error exist in reported facts. It is vital to review such considerations as, "how did the respondent obtain knowledge of the fact--through direct observation, through inference, through heresay, and so on?" (p. 301). Likely accuracy of the respondent's memory needs to be reviewed, as well as motivation for reporting the fact.

Questions also were structured to elicit what the respondent believes the facts to be. For example, questions in the alumni survey pertaining to awareness of discrimination and social distance and attitudes typify this particular kind of question. "In the field of social attitudes, the relationship between objective reality and a person's beliefs is frequently of considerable interest" (p. 303).

A third and final type of question was aimed at ascertaining feelings. Questions related to feelings of burn-out and empathy on the alumni survey are questions of this third type. "An investigation of emotional reactions, if it is to provide a full picture, must uncover not only the individual's feelings but also the circumstances in which the feelings are likely to be aroused" (p. 304).

Nearly all the questions on the alumni survey are fixed-alternative questions as opposed to open-ended questions. The responses on a fixedalternative question are limited to stated alternatives. "These alternatives may be simply yes or no, or they may provide for indicating 
various degress of approval or agreement, or they may consist of a series of replies of which the respondents pick the one closest to their own position" (p. 310). Open-ended questions allow the respondent to answer without regard to a given option and do not provide a limited structure for the response. The main advantage of fixed-alternative questions is seen in the low cost and simplicity of administering and analyzing the data. "A fixed-alternative question may help to ensure that the answers are given in a frame of reference that is relevant to the purpose of the inquiry and in a form that is usable in the analysis" (p. 313).

The alumni survey, in part, is reviewing feelings and attitudes about the Portland State University School of Social Work curriculum. Possible changes may be considered for future participants in the program to better meet the needs of both the students and the community. As with the other areas being explored in the survey, objective research results are more impactful than subjective suppositions. "Since the scientist operates in accord with rational and objective procedures, his conclusions are presumably of a higher quality than the subjective impressions and prejudices of the layman" (Babbie, p. 45).

\section{METHODOLOGY}

The study was conducted by use of a mail survey. A list of 633 former P.S.U. SSW students was compiled. All had received masters degrees between 1971 and 1980.

It was decided to limit our inquiry to 500 (and only the past ten graduating classes) for two reasons. First, printing and mailing expenses demanded some limitations. Second, mailing addresses of alumni 
have not been kept current, so that missing and inaccurate information was a concern throughout the study. After eliminating graduates for whom there was no mailing address, a list of 531 remained. From that list 500 were chosen randomly and were sent the questionnaire.

One hundred fifteen questionnaires were returned, for a response rate of about $23 \%$. Babbie suggests that a response rate of $50 \%$ is "adequate for analysis." His calculation of response rate, however, omits all those questionnaires which could not be delivered to the subjects (1973, p. 165). To save mailing expenses, we did not request a return of undeliverable questionnaires; therefore, we were unable to omit those questionnaires which never reached the selected alumni. We might conclude therefore that our response rate, if calculated according to Babbie's guide, might have been greater. Nevertheless, generalizability is limited throughout the survey because of the relatively low response. During analysis, we attempted to remain sensitive to the fact that statements could be made with certainty only about the 115 respondents.

The questionnaire was redesigned from an existing instrument (University of Tennessee School of Social Work, Alumni Survey, 1979). In making the questionnaire specifically relevant to P.S.U. SSW, three major content areas were included. The first, employment history, inquired about post-MSW work experience (current and first jobs). Questions included weekly number of hours worked, setting, funding source, salary, and activities.

The second content area included inquiries about curriculum at P.S.U. SSW. Questions focused, for example, on helpfulness of specific curriculum areas (measured on a fine-point Likert scale); listing the two most (and 
two least) helpful courses; recommendations about additions to curriculum; and interest in further education.

The third content area of the questionnaire focused on personal and demographic information. In addition to questions about age, sex, and race, questions also were included regarding dates entered and graduated from the school, track (direct or planning), specializations, field placements, work experience prior to graduate school attendance, and present professional affiliations.

The latter part of the survey included questions relative to each group member's individual interest area:

- Questions \#45 through \#47: Self-assessment of job performance and use of clinical interventive techniques.

- Questions \#48 through \#49: Awareness of discrimination in the respondent's agency--in hiring practices, service delivery, and personally.

- Questions \#50 through \#54: Rating of career satisfaction, and relation to curriculum track.

- Questions \#55 through \#59: An assessment of professional burn-out and empathy.

- Questions \#60 through \#64: An assessment of social distance/ prejudice.

- Questions \#65 through \#70: A scale of social welfare policy attitudes .

The instrument was pre-tested informally by asking 10 or 12 acquaintances of group members (who had received MSW's from institutions other than P.S.U.) to complete the questionnaire. The responses indicated that 
with minor revision the questionnaire was readable and easily understood, taking about 20 minutes to complete.

The questionnaire was printed as a booklet with 12 pages, each approximately $63 / 4$ inches by $8 \frac{1}{2}$ inches. The outer cover was designed in such a way as to include a fold-over flap (used for return mailing) which included the P.S.U. address and the pre-paid return postage. The mailing address to the alumnus was easily removed to provide anonymity. A short statement on the inside front cover explained the purpose of the survey and the intention to use responses only confidentially and in aggregate.

The questionnaire was designed with the use of computerized data analysis in mind. From the instrument, a code book was made, from which individual responses were coded and eventually key punched.

SPSS statistical techniques were used to analyze the data. General frequencies were computed for each question. These statistics were used to provide descriptive information about respondents. The general frequencies were used also by group members in testing hypotheses relative to individual interest areas. Cross-tabular analys is was the principal method used. Thus the attempt was to discover associations or relationships, most often between an independent variable and a single dependent variable. In using cross-tabs, Chi-square, phi coefficient and Fisher's exact were used as tests of significance. In all cases, a 95\% confidence level was accepted as significant.

\section{ANALYSIS OF RESULTS}

Alumni responding to this survey were quite selective in questions 
answered. Due to the construction of the questionnaire, certain questions were "selected out"--that is, respondents were directed to NOT answer. With only a few exceptions, respondents complied with these directions. Other questions were not answered by some respondents, and the reasons are not clear. It is surmised that the questionnaire may have been perceived as "too long"--indeed several comments were written in by respondents to this effect. In other cases, such as the self rating questions, it may be supposed that respondents chose not to answer due to feelings that the ratings did not apply to themselves, or that they did not see a purpose to the questions--such a notation was appended to one questionnaire. In certain instances, the construction of the questionnaire itself, rather than the content of the question, may have been at fault. For example, there were cases where additional information was asked, but the question appeared immediately adjacent to a previous question and may have been seen as part of the former question.

Respondents were heavily concentrated in three degree years--1976 $(10.5 \%), 1978(11.4 \%)$, and $1980(24.6 \%)$. No particular significance can be attached to this, other than the fact that the mailing lists for the 1980 graduates were probably the most correct as they were the most recent. Since developing a valid mailing list was one of the major obstacles in this survey, this unusual grouping of response is merely that--unusual.

Respondents had entered the Portland State University School of Social Work from 1962 through 1978. Only 8\% indicated that they had attended P.S.U. SSW on a part-time basis. The part-timers spent from three to seven years completing degree requirements, with half indicating it took three years. 
Sixty-six percent of our respondents were between the ages of 24 and 35 when they received their MSW's; $21.9 \%$ of that amount were between the ages of 27 and 29 . Those 41 or over accounted for $18.4 \%$ of MSW recipients.

Respondents were overwhelmingly female (74\%) and white $(94.6 \%)$. Likewise, a large majority were married (64.6\%). Of those responding to the questions about children, $65 \%$ indicated they had one child, while $46 \%$ indicated they had two, and $23 \%$ indicated three. The number of children reported ranged as high as ten, as reported by one of our alumni. Although the median age of our respondents, as reported, was 35.5 years, several reported that they were over 60 and retired. Our youngest respondent was age 25 .

Although P.S.U. SSW tends to discourage students in the MSW program from being employed during graduate studies, nearly $56 \%$ of our alumni reported having been employed during their graduate education. Of these, only $6.1 \%$ reported having been employed full-time, while nearly $37 \%$ were employed on a part-time basis. Another 19\% indicated they worked summer(s) only while graduate students.

Ninety-five percent of our alumni responded to the question about social work experience prior to entering the School of Social Work, with reported employment of from none to more than twenty years. The median period of employment prior to entering graduate school was nearly four years. It appears that a large portion of our alumni were well acquainted with social work before contemplating graduate school.

As expected, our alumni were heavily concentrated in the direct service track while in graduate school $(83 \%)$. The remaining $17 \%$ were in 
the planning and management track, including community organization. Portland State University School of Social Work has had several specialized programs within its graduate programs, but our respondents showed some confusion in their responses, with one indicating that he was in all three tracks, a rather doubtful possibility. However, $13 \%$ of our respondents indicated they were in the community mental health track, with another $1.7 \%$ indicating participation in the Program Evaluation track and a mere $.9 \%$ reporting participation in the Alaskan Native/Native American track. Further evaluation of this data may be of interest to future students, who might wish to compare these responses to the actual numbers who are known from school records to have been in these tracks. The perception of this response is that it is probably not representative of the actual numbers, but only of our mailing list.

Our graduates responded nearly en masse to queries regarding satisfaction/lack of satisfaction with their P.S.U. SSW graduate education, with $98 \%$ offering an opinion. Slightly more than $20 \%$ indicated some degree of dissatisfaction, while over $45 \%$ stated they were "somewhat satisfied." Nearly $35 \%$ indicated they were either quite or very satisfied with the education they received in graduate school at P.S.U. It is interesting to note that while such a large number of graduates indicated some degree of satisfaction with P.S.U. education, they were just as quick to critique classes and coursework they had taken and perceived as non-helpful.

Graduates saw most helpful courses very similarly, with large dramatic groupings seen. Direct service methods courses were selected by $45.3 \%$ of our graduates as one of the most helpful courses, while field placements were selected by $31.2 \%$. Other choices were well scattered, 
with Human Behavior and Social Environment coming in as poor thirds, at 12.5\%. (It might be noted that this same course grouping, Human Behavior and Social Environment, was well represented in the least helpful course as well, with $25.7 \%$ listing it there.) Graduates' reasons for selecting a course as most helpful ranged from $79 \%$ who felt it was valuable for the "knowledge gained" to $60.5 \%$ listing "skills learned" as a reason for their selection. It should be noted that more than one choice could be made, and usually was. The effect of the instructor was listed as a reason for the course being helpful in $51 \%$ of cases. A low of $14.5 \%$ listed other reasons.

When asked to reply to the question regarding least helpful courses, our response rate went down. Less than $75 \%$ of our graduates 1 isted either one or two least helpful courses. Some comments were noted to the effect that it had been too long to remember course titles. This may have indeed contributed to the low response rate on this query. However, in the group that did respond with least helpful choices, no dramatic groupings were seen as had been the case with the most helpful courses. Lots of least helpful classes were seen--statistics, an integral part of the core curriculum, was seen as least helpful in $37.9 \%$ of the responses, while 25.7\% listed Human Behavior and Social Environment as a least helpful course. Respondents saw the History of Social Work as a very "nonhelpful" course, with over $20 \%$ listing it here. Research courses felt the sting of rejection, with over $20 \%$ of the respondents listing them as non-helpful courses. Again, reasons given for designating these classes the dubious distinction of being least helpful concentrated on the "knowledge not gained"--over 35\% listed this reason. "Skills not gained" 
was given as a reason in over $29 \%$ of the cases, while the "effect of the instructor" rated $27.4 \%$ of the votes. From our respondents' answers, it can be seen that they, at least, felt that a good instructor made a good course much better, while a poor instructor did not have as much effect on a bad course.

Graduates responded almost lethargically to the inquiry regarding P.S.U. continuing education classes, with $42 \%$ declining to respond at a11. Of those who did respond, $25.5 \%$ indicated a need for specialized clinical classes. Family therapy was listed separately by $12.7 \%$ of those responding, while an identical rate was received for classes in supervision and administration. These responses were very similar to those evoked from the question asking about what classes should be added to the curriculum, in which $11.5 \%$ indicated a need for additional supervision and administration classes while an identical $11.5 \%$ asked for more clinical experience. A vaguely defined request for "more practical skills" to be added to the curriculum was noted by $17.7 \%$ of those responding.

A less than enthusiastic response was evoked by the question about doctoral programs, with only $16 \%$ indicating they were very interested, while $23 \%$ were only somewhat interested. Nearly $62 \%$ indicated little or no interest in a doctoral program. Even though the question that followed asked only those who did have an interest in doctoral programs to respond, in fact nearly $94 \%$ of questionnaire respondents did so, rather obviously skewing the results. Consequently, $66 \%$ indicated a lack of interest in having a DSW program at P.S.U., while $62 \%$ had already indicated no interest in a program per se. Thus, we can probably assume that $4 \%$ of those interested in a DSW program would not be interested in one at P.S.U. 
One respondent did expand on his reply, noting, "I am interested in a program other than at P.S.U. only because I feel that an individual ought to attend different schools in the course of his higher education." Those respondents indicating very interested or quite interested again totaled nearly $24 \%$ of those responding, while slightly less than $22 \%$ indicated they were somewhat interested in a P.S.U. program. It is difficult to interpret this data. It appears that some graduates would be interested in a doctoral program only if it were at P.S.U.--perhaps due to its accessibility--while others would not be interested in a doctoral program no matter what the location. Again, the structuring of the questionnaire may have contributed to the confusion in answering this set of questions.

A ninety-six percent response rate was observed when questions were asked about a desire for further services from the School. Even those who did not desire services felt impelled to say why--such as, "I am not in the area any longer." It would appear that this is an area in which graduates feel quite interested. Nearly two-thirds of those responding asked for workshops, while the second request, for job placement services, dropped to $39 \%$--still a very respectable level. A request for summer institutes ran a very close race with job placement requests, with $38 \%$ requesting this service. Graduates also were interested in certification programs, with $35 \%$ asking for clinical practice certification programs and $23.5 \%$ asking for programs in social management certification. Other services requested from P.S.U. included such amenities as use of the recreational facilities and, interestingly, use of library facilities.

With a $96.5 \%$ response rate, P.S.U. SSW graduates indicated only $66 \%$ were members of at least one professional organization. One might draw 
any number of conclusions from this interesting response, none of them backed by particularly good data. One supposition might be that social workers cannot afford to belong to professional organizations! Another might be that the profession is not particularly cohesive, and thus does not, at this point, require any noticeable allegiance to professional groups. Yet another conclusion might be that social workers do not feel that current professional groups offer enough to entice them.

Only $75 \%$ of our graduates responded to inquiries about current earnings, with salaries reported throughout the entire range of less than $\$ 7,000$ to more than $\$ 30,000$. A concentration of $23.6 \%$ was reported in the $\$ 20,000$ to $\$ 25,000$ range, with $51.9 \%$ of our graduates reporting the $\$ 14,000$ to $\$ 20,000$ range. Again, due probably to our much maligned mailing list, $71.3 \%$ of those responding to the question as to job location indicated it was in either the Portland metro area or western Oregon. It should also be noted that no questionnaires were sent outside the United States.

\section{E. SUMMARY}

In sum, our "average" respondent was 35.5 years old, female and white, married with at least one child. She graduated in the late seventies, and had about four years of social work experience prior to entering graduate school. She works in the Portland metro area, and earns around $\$ 18,000$ a year full time. She prefers to work full time. She feels that her education at the Portland State University School of Social Work was not totally satisfactory, but was sufficient. She thinks that there ought to be more classes in clinical social work included in the curriculum, and that the Department of Continuing Education ought to offer the same 
sort of things to help those who graduated without them. She is really not a11 that interested in going on for a graduate degree beyond her MSW, but does wish that P.S.U. would offer some services to its graduates, such as workshops, summer institutes, and certification programs. She thinks that the most important things that she studied while a graduate student were direct service methods courses, and feels the field placements were very valuable. Generally, she does not think that her statistics courses or her research courses were of much use to her. She rates the impact of good teachers in good courses much higher than she rates the impact of "bad" teachers in courses she saw as not useful to her. She generally belongs to at least one professional organization. She probably got her degree when she was not quite thirty and went to work shortly thereafter. She rates herself pretty highly on a job performance scale, seeing herself as above average in most everything except knowledge of theory. 
II. Description of Alumni

\section{A. PROBLEM STATEMENT}

Job title and setting give us a general idea of what social workers are doing. Questions 6 and 14 were designed to elicit more specific information about the activities in which social workers are engaged and the relative amount of time these activities consume. These questions are identical in format; but Question 6 pertains to current employment, while Question 14 refers to the first social work job for those whose current employment is not their first social work position.

\section{B. METHODOLOGY}

A list of seventeen activities was drawn up from previous surveys and the experiences of several social workers. There is also an "other" category for writing in activities which have not been included in the list. Respondents were asked to choose the five activities which occupy most of their time and rank order them from 1 (most) to 5 (least).

In order to obtain an overall rating of which activities consumed the most time, values were assigned to each rank. The highest rank (1) is given the highest value (5). In descending order, then, rank $2=4$, rank $3=3$, rank $4=2$, and rank $5=1$. Numerical values were then compiled by computing the summation of frequency multiplied by rank for each activity. For example, in Question 6, Direct Service to Individuals received $45 \# 1$ rankings, $13 \# 2,2 \# 3,3 \# 4$, and 1 \#5 ranking. The summation value was obtained as follows: $45 \times 5+13 \times 4+2 \times 3+3 \times 2+1 \times 1=$ 290 .

Percentages were also calculated with in each rank. Percentages 
refer to the number of respondents giving a particular activity a particular rank based on total number of responses within that rank. For example, $49.5 \%$, or 45 respondents, ranked Direct Service to Individuals as their most time consuming activity (\#1) based on the 91 respondents who gave any activity a \#1 ranking.

Differences in the total number of respondents to the survey and the number of respondents in Questions 6 and 14 were due to alumni who were not employed, not employed in social work, or who simply failed to answer the questions. The responses to Question 14 represent a smaller sample because several respondents are still employed at their first social work job.

\section{ANALYSIS OF RESULTS}

For both current and first jobs, Direct Service to Individuals received the highest summation value (290 and 152 respectively) and the highest percentage of $\# 1$ rankings $[49.5 \%$ (45 of 91) and $38.9 \%$ (21 of 54)].

Direct Service to Families was the second most time consuming activity in both job categories. Summation values equal 158 for current job and 110 for the first job. This corresponds to $12.1 \%$ (11 of 91 ) and $14.8 \%$ (8 of 54 ) of the \#1 rankings, respectively.

Supervising Staff Members was ranked third for current employment (S.V. = 113) tied with Consulting with Staff Members (S.V. = 113). Although Supervising Staff Members received a greater percentage of \#1 rankings, $12.1 \%$ (11 of 91) versus 3.3\% (3 of 91), Consulting with Staff Members received higher percentages for second, third, fourth, and fifth. As might have been expected, Supervising Staff Members received a 
much lower rating for first jobs (S.V. $=19$, ranked 12th). Instead, Consulting with Staff Members was ranked third (S.V. $=87$ ).

At the other end of the scale, the activities which consumed relatively less time for current employment were Meeting with Public Officials (S.V. $=0$ ), Fund Raising (S.V. $=8$ ) and Meeting with Community Groups (S.V. $=12$ ).

For first jobs the lowest rankings went to Fund Raising (S.V. $=0$ ), Budgeting-Financial Planning $(S . V .=11)$ and Meeting with Public Officials (S.V. $=17)$.

For more complete information see Table II-A which compares the ranking of activities in Questions 6 and 14 according to summation value. The rankings show a close correspondence with the exception of Supervising Staff Members, which was discussed above. 
TABLE II-A

Social Work Activities Ranked by Summation Values

\section{Activity}

Direct Service - Individuals

Direct Service - Families

Supervising Staff Members

Consulting Staff Members

Attending Staff Meetings

Direct Service - Groups

Writing (Reports, Articles, etc.)

Acting as $\mathrm{Client}$ Advocate

Consulting Other Agencies

Developing New Programs

Staff Development - Training

Other

Planning and Doing Research

Direct Service to Care Givers

Budgeting Financial Planning

Meeting with Community Groups

Fund Raising

Meeting Public Officials
Summation

Value 0.\#6

290

158

113

113

104

91

75

71

60

51

46

31

28

26

21

12

8

0
Summation

Value 0.\#14 Rank

152

110

2

19

87

42

56

71

42

49

25

24

18

23

35

11

24

12

3

7*

5

4

7*

6

9

10 *

13

11

8

15

10*

16

14

*Tie 


\section{SUMMARY}

Social workers spend most of their time providing direct services to individuals and families. They also spend much of their time supervising and consulting staff members.

Relatively less time is spent on fund raising, budgeting-financial planning and meeting with public officials and community groups.

The activities which occupy a social worker's time on his/her first job correspond closely to what social workers will be doing at a later job. The one clear exception is supervising staff members, which increases for later jobs. 


\section{Alumni Evaluation of School of Social Work Curriculum}

\section{A. PROBLEM STATEMENT}

"The professional curriculum for social work draws broadly and selectively from the humanities, from other professions and scientific disciplines, as well as from the knowledge and experience developed by social work" (C.S.W.E., 1971 , p. 56).

The Portland State University Masters of Social Work curriculum consists of a combination of class work, practical field experience and research. Questions 17 through 20 were designed to obtain information on what course material has proven to be most helpful and what course material has proven least helpful.

\section{B. METHODOLOGY}

Question 17 lists various courses and curriculum areas and asks respondents to rate them according to helpfulness from 1 (most helpful) to 5 (least helpful). Categories of course materials were obtained by reviewing course catalogs and consulting with senior faculty members who were familiar with changes in the curriculum over the past ten years. Since it is not possible that every respondent would have taken every course listed, two different procedures were used to rate helpfulness.

As in Questions 6 and 14 of the preceding section, a summation value was derived as an overall measure of helpfulness to all respondents. The summation value was then divided by the individual sample size to derive an average helpfulness score, with 5 representing the highest score obtainable. This helps to give a more accurate representation with regard to a course such as Interviewing Skills. It was ranked 
12th overall but received an average score of 4 . Therefore, the smaller number of respondents who took this course rated it very highly.

Questions 18 and 19, respectively, identify the two most helpful and two least helpful courses. They also ask why these courses proved helpful or not.

Having chosen their most and least helpful courses, respondents were asked to categorize the reasons for their selection with reference to knowledge gained, skill(s) learned, personal effect of instructor or "other." Because of the many variables over the ten years covered by the survey, no attempt was made to link "why" with particular curriculum areas. Instead, we sought a general idea of why courses were helpful or not in terms of the key areas listed above.

Question 20 was designed to take advantage of the experience of social workers. We asked what course material they would like to see added to the curriculum.

\section{ANALYSIS OF RESULTS}

The results of Question 17 indicate that the courses which were most helpful to the greatest number of respondents were Field Placement (Summation Value $=489$, Average Score $=4.4)$, Direct Service Core Practice (S.V. $=367$, A.S. $=3.6$ ) and Human Behavior and Social Environment (S.V. = 331, A.S. $=3.3$ ). Courses in General ranked 4th (S.V. $=326$, A.S. $=$

3.3), followed by Research Practicum (S.V. = 318, A.S. = 3.1) and Social Policy (S.V. $=304$, A.S. $=3.0$ ).

Those courses which were evaluated as least helpful were Statistics $(S . V .=227$, A.S. $=2.3)$, History of Social Work (S.V. $=250$, A.S. $=2.3$ ) 
and Core Research Courses (S.V. $=260$, A.S. $=2.6$ ).

All of the above courses were evaluated by a relatively large number of respondents (98 to 112). The following courses were evaluated by a significantly smaller number of respondents (42 to 75 ).

Social Planning/Management Core Courses were evaluated by seventyfive respondents. This resulted in a summation value of 221 and an average score of 3.0 .

Other Courses Taken as Part of the MSW Program were evaluated by sixty-two respondents. The summation value equaled 275 with an average score of 4.4 .

Thes is was evaluated by fifty-two respondents with a summation value of 155 and an average score of 3.0 .

As discussed above, Interviewing Skills was evaluated by a smaller number of respondents (42), but was highly rated by those respondents (S.V. $=167$, A.S. $=4.0$ ). 
TABLE III-A

Courses Ranked for Helpfulness by Summation Value and Average Score

\begin{tabular}{lcccc} 
Course & Rank & $\begin{array}{c}\text { Summation } \\
\text { Value }\end{array}$ & $\begin{array}{c}\text { Average } \\
\text { Score }\end{array}$ \\
\cline { 2 - 3 } Field Placement & 1 & 489 & 4.4 \\
Direct Service Core & 2 & 367 & 3.6 \\
H.B.S.E. & 3 & 331 & 3.3 \\
Courses in General & 4 & 326 & 3.3 \\
Research Practicum & 5 & 318 & 3.1 \\
Social Policy & 6 & 304 & 3.0 \\
Other MSW Courses & 7 & 275 & 4.4 \\
Core Research & 8 & 260 & 2.6 \\
History of Social Work & 9 & 250 & 2.3 \\
Statistics & 10 & 227 & 2.3 \\
Social Planning & 11 & 221 & 3.0 \\
Interviewing Skills & 12 & 167 & 4.0 \\
Thesis & 13 & 155 & 3.0
\end{tabular}


Table III-A lists the courses with their summation values, average scores and ranks according to both of these measures.

The findings of Question 17 were generally supported by the results of Questions 18 and 19, but there were some exceptions. It should be noted that of 115 respondents given the opportunity to list two most helpful and two least helpful courses, a total of 201 most helpful courses were listed compared to 160 least helpful courses. A wide variety of courses were listed as can be seen in Table III-B.

Field Placement and Direct Service received the greatest number of responses for most helpful course with 32 and 46 respectively. Field Placement also received five votes for least helpful course while Direct Service received 17 . The ratio of most helpful to least helpful ratings for some other courses was as follows: Family Therapy 7-0, Consultation 6-0, Medical Social Work 5-0, Psychopathology 5-0, Interviewing Skills 5-1, Supervision-Administration 5-5, Research Practicum 6-3, Social Planning/Management 13-9, Social Policy 12-11, Human Behavior and Social Environment 19-20, Core Research 8-17, Thesis 2-9, Social Work History 0-20, Statistics $0-31$.

Thesis was rated much more negatively in Question 19 than in Question 17. The larger sample size for Question 17 would seem to give more credence to the previous results. The data of Questions 18 and 19 can more easily be influenced by a small number of respondents with a particularly good or bad experience in any one course area. 


\section{TABLE III-B}

Most Helpful and Least Helpful Courses

\section{Course}

Field Placement

Direct Service Core Practice

Social Planning/Management

Social Work History

Research Practicum

Social Policy

Interviewing Skills

H.B.S.E.

Thes is

Core Research

Psychopathology

Community Mental Health

Statistics

Consultation

Family Therapy

Gestalt Therapy

Behavior Modification

Group Therapy

Medical Social Work

Minorities Courses

Supervision-Administration

Courses Outside SSW

Other Courses in SSW

Total
Number of Respondents Rating Course

Most Helpful

32

Least Helpful

46

13

0

6

12

5

19

2

8

5

4

0

6

7

2

0

3

5

1

5

4

16

201

\section{5}

17

9

20

3

11

1

20

9

17

0

1

31

0

0

0

1

3

0

3

1

1

7

160 
Having identified a course as most helpful or least helpful we then asked respondents to indicate why. The results are indicated below:

\section{TABLE III-C}

Why Most Helpful Why Least Helpful

Knowledge gained

Skill(s) learned

Personal effect of instructor

Other
$39 \%(182)$

$28 \%(132)$

$25 \%(117)$

$7 \% \quad(33)$
$29 \%(81)$

$24 \%(67)$

$23 \%(63)$

$24 \%(66)$

Knowledge gained was cited most often in both categories. However, skill(s) learned and personal effect of the instructor are also well represented. Many respondents listed more than one reason why a course was helpful or not. We have not attempted to assess how these factors interacted.

The respondents to Question 20 (see Table III-D) listed courses that they would like to see added to the curriculum or given additional emphasis. Three related areas received the greatest number of responses. Practical Direct Service Skills, Specialized Clinical Skills and General Clinical Skills received $38.6 \%$ of the responses. The emphas is was on practical and concrete skills. These words were repeated several times. It would appear that many respondents felt that their education emphasized the theoretical over the practical.

Supervision-Administration received $11.5 \%$ of the responses, followed by Developmental Psychology (8.3\%) and Family Therapy (6.3\%).

The "other" category contained $28 \%$ of the responses. These included rural problems, vocational counseling, play therapy, dealing with burnout, additional use of video techniques and many other areas. These 
responses indicate a desire for a much wider range of elective courses.

TABLE III-D

Courses Suggested as Additions to Curriculum

Course

Other

Direct Service Practical Skills

General Clinical Skills

Supervision-Administration

Specialized Clinical Skills

Developmental Psychology

Family Therapy

Minorities Courses

Medical Social Work
Frequency

27

17

11

11

9

8

6

4

3
Percent

28.1

17.7

11.5

11.5

9.4

8.3

6.3

4.2

3.1

\section{SUMMARY}

Respondents rated Field Placement and Direct Service Core Practice courses as the two most helpful courses. Statistics and History of Social Work were rated as the two least helpful.

Knowledge gained is probably the most important factor in deciding whether or not a course has been helpful. However, ski1l(s) learned and personal effect of the instructor also appear to be important factors.

Graduates of the Portland State University School of Social Work have suggested that the school give more emphasis to practical clinical skills. They have also indicated a need for a much wider range of elective courses. 
IV. Assessment of Direct Service Alumni Intervention Techniques

\section{A. PROBLEM STATEMENT}

Question 46 pertains only to alumni engaged in clinical practice.

There are many approaches to clinical practice with different concepts and methods of intervention. Which of the many intervention techniques are currently in use by social workers? Do social workers rely on one particular orientation or do they tend to be more eclectic?

Question 47 inquires about intervention techniques which are thought to deserve additional emphasis in the curriculum.

\section{B. METHODOLOGY}

A list of intervention techniques was compiled from Frances $\mathrm{J}$. Turner's Social Work Treatment: Interlocking Theoretical Approaches (1979). There were additions, such as Neurolinguistic Programming, which are not included by Turner, and unfortunately one major intervention technique was omitted. Transactional Analysis was inadvertently deleted during one of the many transcriptions of the list of intervention techniques.

Twenty-three intervention techniques are listed along with an "other" category which allows respondents to write in any technique not included. Respondents were asked to indicate whether they always, often, sometimes, seldom, or never used each of the listed techniques. As discussed previously for Sections II and III, a summation value was computed for each intervention technique.

The results of Question 47 were compiled in a frequency table indicating which intervention techniques are thought to be most deserving of additional emphasis. 


\section{ANALYSIS OF RESULTS}

Looking at the summation values, we find the Problem Solving Model at the top of the list with a value of 240 . Crisis Intervention is next (212), followed closely by the Psychosocial Model (211). Clustered in the range of S.V. $=193$ to 183 are: Family Therapy, General Systems Approach, Client Centered Therapy, Task Centered Model and Cognitive Approaches.

This survey indicates that the following intervention techniques are the least popular among social workers: Radical Therapy (S.V. = 79), Analytical Therapy (S.V. $=84)$, Encounter Therapy (S.V. $=84)$, and Provocative Therapy (S.V. $=88$ ).

A complete listing of the intervention techniques, ranked according to summation value, can be found in Table IV-A.

Examining the returned questionnaires indicated that the "always" category was the least used. Even those respondents who indicated that they always used a particular intervention technique invariably listed other techniques which they also used. Most of the responses were found in the "sometimes" category. Thus, most social workers sometimes use one intervention technique and sometimes use another, indicating a tendency to try to fit the technique to the situation rather than the other way around.

This eclecticism is also reflected in the responses to Question 47. Many different intervention techniques received a few votes as being most deserving of additional emphasis in the curriculum. Crisis Intervention received the most responses (5). All others received 1 , 2 , or 3 responses. The "other" category contained $33 \%$ of the responses. 


\section{TABLE IV-A}

Intervention Technique Ranked According to Summation Value

Intervention

Technique

Other

Radical

Encounter

Provocative

N.L.P.

Adlerian

Existential

Functional

Gestalt

Psychoana lys is

Ego Psych.

R.E.T.

Role

Reality

Behavior Modification

Cognitive

Task Centered

Client Centered

General Systems

Family

Psychosocial

Crisis Intervention

Problem Solving
Summation

Value

46

$\underline{\text { Rank }}$

23

79

22

84

21

88

20

105

19

115

18

117

17

139

16

145

15

146

14

148

13

153

12

166

11

169

10

172

183

185

187

189

193

211

212

240

\section{3}

1

0 7 
Several different techniques (Hypnosis, Object Relations Theory, Transactional Analysis, Social Action, etc.) received one or two responses each. Table IV-B lists the responses to Question 47.

\section{SUMMARY}

The Problem Solving Model is one of the most popular intervention techniques among social workers. However, the data indicate that social workers tend to be eclectic in their use of intervention techniques. They resist using the same technique for every situation, but choose among several different intervention techniques. 
TABLE IV-B

Intervention Techniques Deserving Additional Emphasis

Intervention Technique

Other

Crisis Intervention

Problem Solving Model

Cognitive Approach

General Systems Approach

Gestalt Therapy

Neurolinguistic Programming

Psychoanalytic Therapy

Psychosocial Model

Adlerian Therapy

Analytical Therapy

Behavior Modification

Client Centered Therapy

Existential Therapy

Family Therapy

Functional Model

Radical Therapy

Rational Emotive Therapy

Role Theory Approach
Frequency

15

5

3

2

2

2

2

2

2

1

1

1

1

1

1

1

1

1

1 


\section{The Relationship Between Program Track and Career Success}

\section{A. PROBLEM STATEMENT}

At Portland State University School of Social Work, as at many universities, incoming students are separated into two program tracks: Direct Service, in which instruction is received on how to help clients directly through counseling and case management; and Planning and Management, in which the emphasis is on managing and planning for social service agencies. Although there is overlap between these two tracks, the Planning and Management track clearly provides more information and experience on functioning at the supervisory or managerial level within a human service agency.

Evidence gathered from sparse research has indicated that regardless of the track from which one graduates the majority of all MSW's employed in the field are spending most of their time supervising others and managing programs soon after graduation. As noted in the Encyclopedia of Social Work, "Direct Service now appears to be a smaller proportion of all social workers' activities" (17th edition, p. 1072).

This suggests that most of those students in the Direct Service track are being mistrained. While they will know how to interview clients, they will be asked to complete employee evaluation forms. They will have learned how to manage a case but will be forced to balance a budget instead.

There are three hypotheses, derived from the above discussion. The first is that the longer an MSW is practicing, the more likely he or she is to end up in a supervisory or managerial position. The second hypothesis is that, regardless of the program track, the job-related tasks 
that each MSW performs will be similar. And the third hypothesis is that MSW's graduating in the Planning and Management track will experience greater career success as a result of the more appropriate and applicable training that they received in the MSW program.

Each hypothes is proposes one association between two variables. In each case a null hypothesis that there is no association can be derived.

\section{B. LITERATURE REVIEW AND METHODOLOGY}

In order to pursue the third hypothes is a Career Success Index was developed. Besides including the objective data of current salary (Question \#7), it would also include the responses to five questions concerning job satisfaction (Questions \#50-\#54). The five areas addressed by these questions are derived from the literature on attitudinal measures of job satisfaction. Brayfield, Wells and Strate in 1957 discerned five factors that affect job satisfaction: 1) supervision, 2) financial rewards, 3) working conditions, 4) confidence in management, and 5) selfdevelopment. Through a statistical analysis of many different questions relating to job satisfaction that were administered to a variety of sample groups, these five areas were found to be the primary factors (1957).

Wherry used factor analys is as a means of establishing the dimensions of job morale. By taking the data from several other studies on morale inventories and analyzing them, he deduced one general factor and five group factors that related to job satisfaction. Similar to Brayfield, Wells and Strate's factors, these were: 1) working conditions, 2) financial reward, 3) supervision, 4) management, and 5) personal development. 
Supervision and the general attitude factors were found to have the greatest invariance value (.90) followed by financial reward (.82), working conditions (.70), management (.57) and personal development (.47) (1958).

Locke et al. administered job satisfaction measures to 133 randomly selected employees from two companies. Comparing the validities of the different areas, salary, promotions, and supervision were shown to have the greatest validity with work and people being weaker but still at an acceptable level. Although the categories are labeled differently than Brayfield, Wells and Strate's or Wherry's, they are still very similar and probably reflect the same dimensions. In general, Locke et al. presented the thesis that job satisfaction is a dependent rather than an independent variable (1964).

Finally, Larsen and Owens assumed that through the use of an "importance indice," in addition to the satisfaction values, the index could be made more accurate. This indice is intended to weight the factors according to their perceived importance to the employees. They constructed their scale while working with the personnel of a Great Lakes shipping concern, and derived the same five factors as Brayfield, Wells and Strate, and Wherry, but titled them 1) general morale, 2) company and management, 3) working conditions, 4) supervision and 5) financial rewards. They found that the inclusion of an importance scale in conjunction with a satisfaction scale, item by item, failed to make the expected contribution (1965).

This overall consensus on the five major factors affecting job satisfaction made it easy to choose the areas that the questions in this 
survey should cover. They are: 1) Supervision, the amount of satisfaction the employee has with the consideration he or she receives from supervisors and the structure of that supervision; 2) Financial Reward, how commensurate the employee feels that the pay and benefits are to the job performed; 3 ) Working Conditions, satisfaction with the work load and setting; 4) Management, how confident the employee is in the fairness, efficiency and communication skills of the management personnel; and 5) Personal Development, as reflected in the perceived job importance and advancement opportunities.

\section{ANALYSIS OF RESULTS}

Of the total survey sample, 91 alumni were currently employed in social work. Forty-one percent of this total were in management positions, such as directors, supervisors, teachers, program coordinators or program evaluators. The other fifty-nine percent were in direct service jobs, such as medical social work, clinical social work and case management. The ratio, as might be expected, of alumni in supervisory or managerial positions, although not statistically significant due to the low number of respondents, was highest for those graduating in the Planning and Management track of the social work program at $82 \%$ (9 of 11 ) and lowest for graduates of the Direct Service track at 35\% (28 of 79) (see Table V-A). 


\section{TABLE V-A}

Percentage of Alumni in Supervisory or

Managerial Positions by Program Track

Direct Service

$(n=79)$

$18(23 \%)$
Planning and Management

$(n=11)$

$6(55 \%)$

The number of alumni functioning as supervisors or managers was found to increase as the length of time since they had earned their degree increased. Of the forty-three alumni who graduated in 1976 or before, 22 or $51 \%$ were in supervisory or managerial positions, as compared to 15 or $31 \%$ of those who graduated in 1977 or more recently (see Chart $\mathrm{V}-\mathrm{A})$. This is a significant difference at the .05 level of significance (chi square score of 104.34 with 108 degrees of freedom, significance $=$ $.018)$. Thus we reject the first null hypothesis of this section of the study that there is no relationship between the length of time practicing social work after graduation and the likelihood of holding a supervisory or managerial position.

This supports to a great degree the contention that many MSW students at Portland State University will not end up in the area of social work that they have been trained for. Over a third of the Direct Service students did not end up in direct service jobs and from the data we can see that this trend increases the longer the graduates are in the field. Considering the fact that this sample was biased toward more recent graduates, this discrepancy is likely to be greater for the complete population of graduates than indicated here.

Further analysis was made of the major activities of the alumni 


\section{CHART V-A}

Percentage of Alumni in Supervisory-

Management Positions by Year of Degree

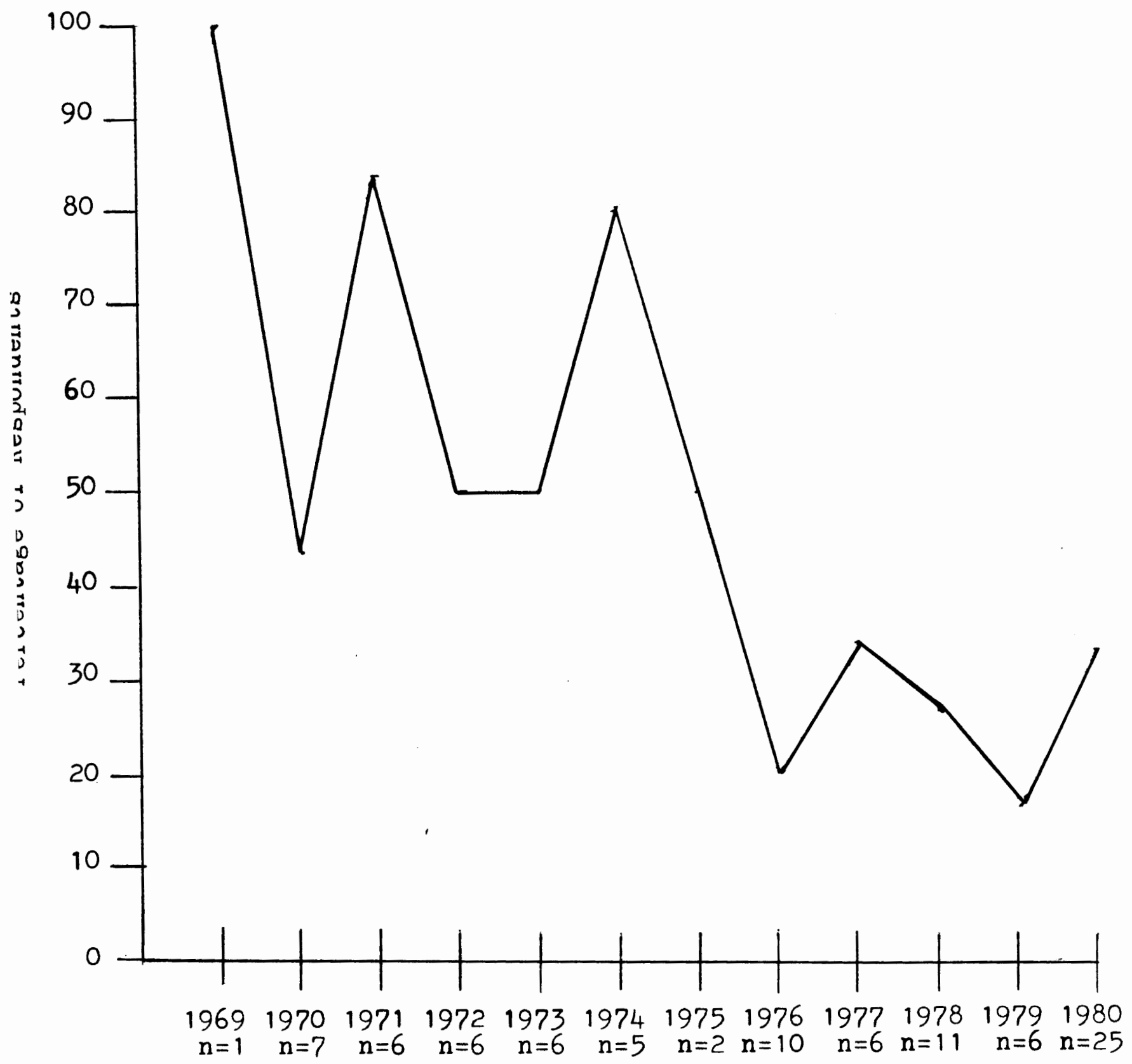

Year Degree Was Awarded 
while at their social work jobs. Note that Table II-A on "major job activities" in Section II uses the five activities requiring the most time in determining the importance of each activity while in this section only the first three activities listed as most time consuming are used to establish that hierarchy. There are, therefore, some minor discrepancies between sections and charts as to the importance attached to the different job activities. When asked to list those three activities occupying the most of their time, direct service to clients and direct service to families were the two activities most frequently chosen by the total sample (cited by $69 \%$ and $41 \%$ of the respondents respectively). "Supervising staff members" (29\%) and "consulting staff members" (27\%) were the third and fourth most common activities.

When compared across the program tracks there were no statistically significant differences between the job activities performed by the alumni. Consequently, we fail to reject the second null hypothesis. However, some interesting tendencies were noted. While direct service to clients and families are the major activities of the graduates of the Direct Service track, they rank only third (40\%) and tenth (10\%) for the graduates of the Planning and Management track (see Chart V-B). Instead, those alumni recorded "developing new programs" and "planning and doing research" as the major activities (both cited by $50 \%$ of the Planning and Management respondents).

Another distinction between the tracks is the involvement in "budgeting and financial planning." Only 3\% of the Direct Service graduates listed that as one of their three major activities while $30 \%$ of the Planning and Management graduates did so. 
It should also be noted that "supervising staff members" is a common activity for graduates of both tracks. Fully $27 \%$ of the Direct Service graduates and $40 \%$ of the Planning and Management graduates cited that as a major activity. In addition, $31 \%$ of the Direct Service graduates listed "consulting staff members" as one of their top three activities.

These figures point out several things. First, it would appear that there is some difference in the tasks that Direct Service graduates and Planning and Management graduates are being asked to perform on the job. Direct Service MSW's are much more involved in direct service activities while Planning and Management MSW's are concentrating more on setting up new programs and researching those already in effect. Monetary matters are almost exclusively the domain of Planning and Management graduates.

Secondly, both tracks have quite a bit in common. Both seem to be spending considerable time consulting and supervising staff members. Although to a lesser extent than Direct Service graduates, many Planning and Management graduates perform direct service functions.

As a measure of career success, an index was devised which combined salary earned in the current social work job with job satisfaction according to the following formula:

Career Satisfaction $=2($ SALARYC $)+($ SATSUPER + SATSALRY SATCNDTN + SATMNGM + SATSLFDV)

where SALARYC is an ordinal category for current job salary (see Question \#7 of the questionnaire) and SATSUPER, SATSALRY, SATCNDTN, SATMNGM, and SATSLFDV are the five Likert measures of job satisfaction (see Questions $\# 50-\# 54$ of the questionnaire, note that the Likert scale values were reversed from the questionnaire so that they would correspond to the 


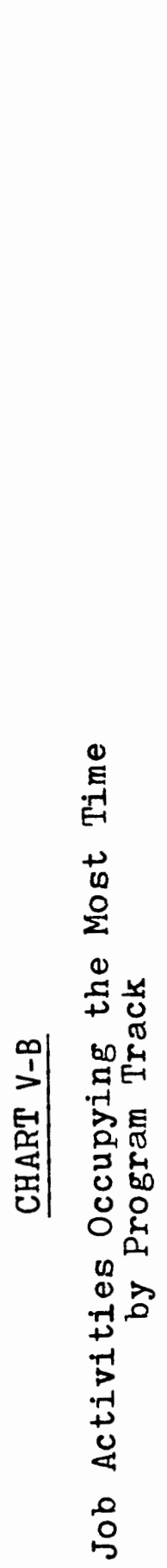

Direct Service to Care Givers

DII Meeting with Community Groups

Consulting with Other Agencies

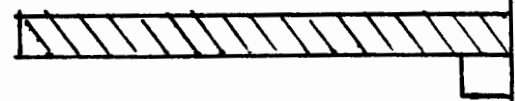

Planning and Doing Research

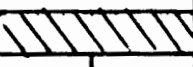

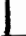

Writing Reports and Articles

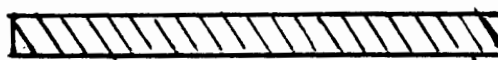

Developing New Programs

Fund Raising

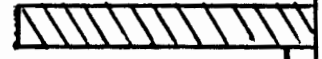

Budgeting and

Financial Planning

Attending

Staff Meetings

Consulting

Staff Members

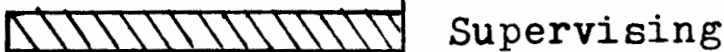

Staff Members

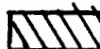

Staff Development and Training

Acting as Client Advocate

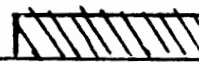

Direct Service to Groups
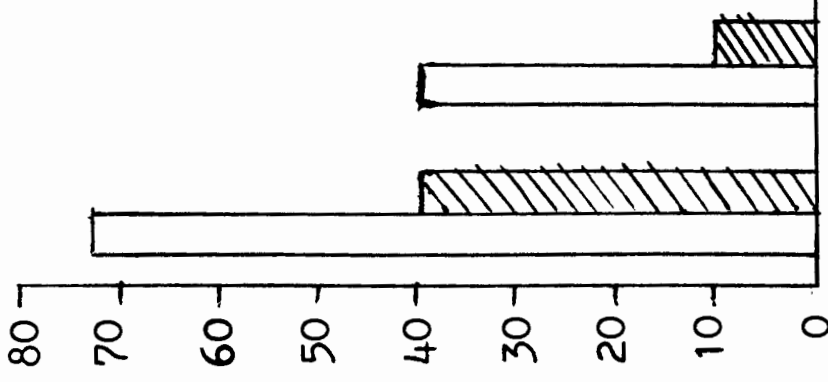

Direct Service to Families

Direct Service to Clients 
SALARYC values).

In Table V-B, this index was condensed so that a score of 34 or higher was registered as a successful career and 33 or less as an unsuccessful career, the division being at this point since 33 was the median score. When the resulting figures were compared across tracks, the results were not significant (chi square score of .007 , with a significance of .932). Graduates of both tracks were almost as likely to be successful as unsuccessful, with $43 \%$ of the Direct Service track graduates registering as successful as compared to $50 \%$ of the Planning and Management track graduates.

\section{TABLE V-B}

Percentage of MSW Graduates with Successful Careers Compared by Program Track

Direct Service

$(n=70)$

$43 \%$
Planning and Management

$(n=10)$

$50 \%$

Therefore, the third null hypothes is that there is no relationship between program track graduated in and the amount of career success cannot be rejected.

\section{SUMMARY AND RECOMMENDATIONS}

It must be noted in the beginning that the small number of Planning and Management graduates responding to the questionnaire has prohibited the statistical proof that can be established in this study but some trends have been observed.

Graduates of both tracks are equally as likely to experience career 
success. Over time, all MSW's tend to end up in supervisory or management positions, with graduates of the Planning and Management track getting there possibly a bit more quickly.

The job related tasks that MSW's are asked to perform do vary slightly between the tracks but staff supervision activities are common to both. Direct service to individuals also occurs frequently for graduates of both tracks, although to a lesser degree for Planning and Management alumni.

It would seem then that the training in both tracks of the Portland State University Masters of Social Work program are deficient in some areas. Since staff supervision and consultation are such important activities for graduates of both tracks, training in this area should be a high priority. Presently, this does not appear to be the case, with Planning and Management students receiving only a minimum amount of supervisory training and Direct Service students even less. Course work in this area should be required of all students in the MSW program.

There is a definite lack of support in this study for the hypothesis that Planning and Management graduates would experience greater career success than Direct Service graduates. One explanation of this is that students in both tracks are lacking course content that they need, rather than just the Direct Service students as originally premised. Some measure of counseling or interpersonal skills training would seem advisable for Planning and Management students as this is one of their major job requirements. This is almost entirely missing in the present program. As it currently stands, most of the training in these areas is probably taking place in the field during that period following graduation but 
preceding advancement into supervisory positions.

Direct Service students, conversely, are well versed in interpersonal skills but are lacking in the practical skills necessary to run an agency and to manage subordinate staff. Some exposure to the Planning and Management courses already a part of the curriculum would appear to be the simplest solution to this deficiency.

Possibly the best avenue to providing this training before graduation would be the transfer of some courses that are presently in the core program for only one track to a dual track status. Open the course on staff supervision to all MSW students rather than just to $\mathrm{Pl}$ anning and Management students. Open the introductory Interviewing Skills course to Planning and Management students as well as Direct Service students. This would offer all MSW students, as one respondent suggested, an education in "practical management." 
VI. Alumni Awareness of Discrimination in Hiring, Service Delivery and Personal Experience

\section{A. PROBLEM STATEMENT}

Since the social reform movement of the 1960's, the term "discrimination" has been highly visible. The use of this term has drawn social attention to prejudicial treatment of the poor, then to non-whites, and now the women's movement is directing society's attention towards discrimination because of sex. Pressure has been placed upon employers and legislators to include anti-discriminatory statements in policy. Legislation is being lobbied for, and occasionally adopted, which insures individual rights to some people of minority status. The National Association of Social Workers in response to this concern has included in its code of ethics the following pledge:

The social worker should not practice, condone, facilitate, or collaborate with any form of discrimination on the basis of race, color, sex, sexual orientation, age, religion, national origin, marital status, political belief, mental or physical handicaps, or any other preference or personal characteristic, condition, or status.

NASW's code of ethics is an expanded definition of discrimination going beyond prejudicial treatment because of race, sex, or age to include prejudicial treatment based on any personal difference. Such an optimistic pledge by social workers hopefully would be reflected in social service agencies, manifesting itself by non-discriminatory services delivery, policies, and employment practices. Yet, there is almost no empirical data which shows that the increased visibility of the term "discrimination" has had much effect on the actual practice of prejudice in social work. Council of social work education has included among its criteria for certification that social work schools' curricula 
include minority studies. Social work schools are urged to recruit minority students; NASW pledges non-discrimination in service to clients. Clearly there is a move within the field to make social workers more aware of discrimination. Yet, are social workers even aware of discriminatory practices in their agencies?

We propose through our questions to look at "awareness of discrimination" in relationship to several independent variables--sex, age, and curriculum track. Women's liberation and recent Grey Panthers have heightened the visibility of discrimination because of sex and age. We wish to see if there is any relationship between the sex or age of the respondent and his/her awareness of discrimination. We hypothesize that women will be more aware of discrimination than men, and that older people will be more aware than younger respondents. We also hypothesize that students who were in the direct service track will be more aware of discrimination than those in the planning track.

\section{B. LITERATURE REVIEW}

Our soliciting the respondents' "awareness of discrimination" is based on an assumption that discrimination exists in most agencies to some degree. A review of significant literature in the social service journals supplies several studies which support this thesis. Belon and Gould's study looked at salary differential between men and women in social service agencies. They concluded that indeed salaries are inequitable, for although women outnumber men in the field, men receive proportionally higher salaries (1977). Knapman's study of family agencies concurs with Belon and Gould, reporting that salary differential between 
men and women is clearly discriminatory. Figueira-McDonough published an extensive review of literature dealing with discrimination in social work. She notes the evident dearth of empirical information and emphasizes the need for the issue of discrimination to be put on the agenda for social researchers. Her study does conclude that available data from the 1960 's and '70's show a slight improvement in the situation of Blacks in human service organizations, and no improvement in the situation of women (1979). Kasschau in a study of Los Angeles residents who were Black, Mexican-American, and white found that an overwhelming majority of people ages 45-74 reported experiences with race and age discrimination in finding and staying on a job. We were unable to find literature which looks specifically at discrimination for reasons other than race/ethnicity, sex, or age (1977). The most significant literature exists on discriminatory practices because of sex. Perhaps the lack of information about prejudicial treatment in other areas is due to the only recent social concern generated by other minority groups finally speaking out for their rights. The bulk of the social service literature in journals deals with proposals of models for working with minority clients. The volume of this literature suggests an awareness of discrimination on the part of many published social workers, but we are unable to find studies looking at the awareness of the non-academicians who are practicing in the field.

\section{METHODOLOGY}

The procedure for measuring "awareness of discrimination" could not turn to previous studies for reliable instruments since none could be 
found. There are available measures for "prejudice," but these instruments examine the prejudice of the respondent. In this section, we did not want to measure the individual's personal beliefs, but rather the individual's observation of the prejudice-in-action (discrimination) which surrounds him/her. Limited by space and lack of a tested instrument, we chose the simplest approach of asking directly if the respondent was aware of discrimination in the agency. We chose to break down "awareness of discrimination" into three categories: awareness of discrimination (1) in hiring, (2) in service to clients, and (3) discriminatory treatment through personal experience. If respondents were aware of discrimination, they were given the option of rating the degree of discrimination they had observed or experienced by using a three-point scale: often, sometimes, or rarely. Respondents who were unaware of discrimination could record this by responding with the number corresponding to "not aware." Finally a fifth response of "not applicable" was offered. Respondents were asked to report the degree of discrimination of which they might be aware in eight categories: sex, age, race/ethnicity, sexual preference, religion, income status, handicapped status, and political idealogy. These eight criteria were taken from the NASW's code of ethics.

\section{ANALYSIS OF RESULTS}

The response rate for the questions on discrimination was very low. Each respondent had an opportunity to answer twenty-four possible questions on discrimination (eight types of discrimination multiplied by three areas of discrimination). Of the 115 people responding to the 
questionnaire, about one-half either marked the section on discrimination "not applicable," or left the entire section blank. Analys is of graduates' "awareness of discrimination" is therefore drawn from only fifty to sixty responses. In order to increase the numbers for our analysis, we collapsed the data from twenty-four into three categories of discrimination--that in hiring, in service delivery, and through personal experience. By assigning a value of " 3 " to "very aware of discrimination," "2" to "somewhat aware," "†" to "rarely," and "0" to "not aware," each of these three categories could have a possible score of "24." Each of the eight types of discrimination--because of sex, age, race/ethnicity, sexual preference, religion, income status, handicapped status, and political idealogy--could receive a possible value of " 3 " for "awareness of discrimination" often. "Three" multiplied by the eight types of discrimination renders the possible summarized value of "24" for awareness of discrimination in hiring, service delivery, and through personal experience.

The collapsed variable summarizing "awareness of discrimination in hiring" was responded to by sixty people ( $52 \%$ of the total respondents). of those who responded, forty-five were not aware of any discrimination. The fifteen respondents who were aware had scores ranging from " 1 " to "14." "Awareness of discrimination in service delivery" showed the same pattern of response. Fifty percent did not respond; seventy-nine percent of those who did respond were unaware of discrimination in service delivery. One person received a summarized score of "10," which was the highest value recorded. The variable summarizing "awareness of personal discrimination" had an even lower response rate than the preceding two 
variables. Sixty-four people, or fifty-eight percent of questionnaire respondents, did not answer this section. Eighty-two percent of those who responded were unaware of personal discrimination.

The data was also collapsed into the eight categories of age, sex, race/ethnicity, sexual preference, religion, income status, and political idealogy; these variables combined the respondent's awareness across the area of hiring, service delivery, and personal experience. A respondent who was often aware of discrimination in these three areas could receive a possible score of "9" for each of these eight variables. Fourteen respondents were aware of discrimination because of sex. Nine people were aware of discrimination because of sexual preference, race, and age. No one received a score of "9."

To test our research questions looking at the relationship between "awareness of discrimination" and the sex, age, and curriculum track of the respondent, we used the statistical test for significance of the Chi Square. We set up nine two-way tables using the three dependent variables of awareness of discrimination in hiring, service delivery, and through personal experience and the independent variables of sex, age, and curriculum track. None of these nine correlations tested to be statistically significant.

When interpreting the data, it is important to keep in mind the very small sample size of this study, and the even smaller number of respondents answering the questions on discrimination. Such small numbers severely inhibited the scope of the study. Correlations which one might wish to make between "awareness of discrimination" and the race/ethnicity of the respondent, for example, were impossible because 
ninety-five percent of the respondents were Caucasian. Our crosstabulations can neither prove nor disprove significant relationships because the representative numbers in each cell are just too small. For example, the cross-tabulation examining the relationship between "awareness of discrimination in hiring" and the sex of the respondent had a total number of only fifty-nine respondents. Of those who had no awareness of discrimination, thirty-two were female and twelve were male. Of those who were aware, eleven were female and four were male. These numbers are not large enough to show any statistical relationship between sex and awareness of discrimination. All other eight cross-tabulations had this same drawback.

The data does dramatically show, however, that most social workers are not aware of discrimination in hiring, service delivery, or through personal experience. Of those who responded, about eighty percent were unaware of discrimination. The ones who did not respond either skipped the questions or marked them "not applicable." In either instance, a respondent who did not answer this section was by omission showing a lack of awareness of discrimination. Counting non-responses as "lack of awareness," then only ten to fifteen percent of the questionnaire respondents were even aware of discrimination. Those who were aware still recorded that the instances of discrimination were rare.

\section{E. SUMMARY AND RECOMMENDATIONS}

Are we to conclude then that discrimination in social service agencies staffed by P.S.U. School of Social Work graduates is almost non-existent? If we assume that these graduates are aware of dis- 
crimination, then by report of those graduates sampled, there exists very little discrimination in the field. Yet, the literature, personal observation, and common sense all question such an observation. It seems more reasonable to assume that the respondents are not very aware of the discrimination which surrounds them in their agencies. At best, only twenty percent of the respondents were even aware of any discrimination. Those who responded only noted rare occurrences.

Although the data is too small to give any useful information about relationships between "awareness of discrimination" and some independent variables, the data does strongly suggest that P.S.U. School of Social Work graduates are aware of discrimination in neither hiring, service delivery, nor through personal experience. The implications of such an observation might be that the Social Work curriculum at P.S.U. is weak in sensitizing the student to minority concerns and to issues of discrimination. We suggest that a curriculum which strongly emphasized minority issues would heighten the student's awareness of discriminatory practices around him/her. From the results of this study, we recommend that such changes in curriculum be realized in order that P.S.U. graduates can enter the working world as well-equipped and sensitive social agents. 


\section{Minority Prejudice as it Relates to Alumni Social Work Practice}

\section{A. PROBLEM STATEMENT}

This section of the Alumni Survey attempts to measure the prejudicial attitudes of graduates and the amount of contact these graduates have with minority clients. Minorities are defined for the purpose of this survey as the larger non-white population groups; i.e., Blacks, AsianAmericans, Hispanics and Native Americans. Prejudice has been defined by Gordon Allport in his classic study, The Nature of Prejudice, as, "A judgement based on previous decisions and experiences; a judgement formed before due examination and consideration of the facts--a premature or hasty judgement; an emotional flavor of favorableness or unfavorableness that accompanies such a prior and unsupported judgement" (1958, p. 6). The assumption that is being made here is that minority discrimination, the observable outcome of the attitude, "minority prejudice," will be demonstrated by the amount of minority client contact of social work graduates. The test hypothes is is, the more contact with and knowledge about minorities social work students have, the less prejudice they will demonstrate.

\section{B. LITERATURE REIVEW}

As previously stated, NASW, in its code of ethics, has addressed discrimination and our obligation to eliminate discriminatory practices within the field of social work. Also addressed is our responsibility to practice social work in the best interests of client and society.

In addition to NASW, many social work educators are concerned with the lack of minority content within the curriculum. One of them is 
John 01 iver, who says, "The lack of movement by schools of social work in the direction of achieving minority-relevant curricular goals is an embarrassment to the profession, and detracts from students acquiring the necessary skills to be effective practitioners in minority communities" (1979, p. 106).

0liver, in an article proposing a model for integrating minority content in the social work curriculum, suggests that, "The profession's policy statements are fully supportive of the inclusion of this content, and therefore it is reasonable to assume that the lack of success is directly attributable to poor, perhaps racist faculty attitudes" (1979, p. 106).

Probably the foremost researcher on the nature of prejudice, Gordon Allport, states that contact and education are two of the most important elements in countering the effects of social prejudice. He says that only the type of contact that leads people to do things together is likely to result in changed attitudes (1985, p. 276). Says Allport, "Prejudice (unless deeply rooted in the character structure of the individual) may be reduced by equal status contact between majority and minority groups in the pursuit of common goals. The effect is greatly enhanced if this contact is sanctioned by institutional supports (i.e., by law, custom, or local atmosphere), and provided it is of a sort that leads to the perception of common interests and common humanity between members of the two groups" (1958, p. 281). If this is true, then students experiencing greater contact with minorities and students receiving minority-relevant curriculum content as well as enhanced contact with minorities, particularly if these minorities are other students, could 
be expected to display an increased tendency to work with minorities and to work more effectively with minorities. However, the specific nature of the Portland population makes this a difficult hypothes is to test.

First, there are relatively few minorities as compared to some other cities of equal size and secondly, what minorities there are, are often denied these social work services due to their minority characteristics, i.e., income or cultural disinclination to seek this type of service.

This survey, then, will look at the relationship between the degree of minority prejudice of the social work graduate and the amount of minority client contact in their current practice of social work.

\section{METHODOLOGY}

Survey methods have been described previously. This section followed the broader Alumni Survey methodology. Questions \#60-\#64 relate to this section of the survey. These questions focused on two areas: the client population respondents work with and degree of prejudice of the respondents as measured by a "social distance" scale.

In designing an instrument to measure prejudice we had hoped to develop a scale based on the client population of social work alumni. However, given problems with the sample population this was not possible. We encountered two significant problems with the survey responses. One, virtually all respondents work in the Portland metropolitan area which has a minimal minority population. It is reasonable to expect that non-prejudicial social work graduates could have minimal contact with the minority population. Also, we received 
a small response to our survey questionnaire (20\%) which raises the question of the representativeness of our sample.

There also were problems with the instrument design. The client population descriptive categories were not mutually exclusive. For instance, respondents were asked to describe the clients they most often work with, in terms of "elderly or handicapped," as well as "racial minority." Respondents could have a client fitting all three categories and yet had to choose only one to describe their client.

A second part of the instrument involved a "social distance" scale. Questions \#61-\#64 relating to this area are fashioned after the original research linking prejudice with social distance. E. Bogardus (1933) was one of the first to use the scale concept in measuring attitudes. His social distance scale, which has become a classic technique in the measuring of attitudes toward ethnic groups, is composed of a number of items selected so as to provide a measure of the degree of social acceptability of any nationality group (Jahoda, et a1., 1951, p. 188).

The individual's attitude is measured by the closeness of relationship that he/she is willing to accept (Jahoda, et al., 1952, p. 188). This questionnaire used three questions which, combined, composed a social distance index labeled, "Socdist." Each question had a continuum response range of 1-5, labeled correspondingly, always, often, sometimes, seldom, and never. The index of possible response scores ranged from 3 to 15 .

Socdist was then divided into two categories: "high socdist" including a response index score of 8-highest, and low socdist indicated by response index score of lowest-7. Low socdist indicates a lesser prejudicial attitude and a high socdist score indicates a greater 
prejudicial attitude.

Results of these two categories, social distance and client population, were compared in a two-by-two cross-tabulation table (see Table VII-A). This table compares respondents with both high and low social distance scales, with responses indicating work with minority clients and non-minority clients (containing all remaining categories).

\section{ANALYSIS OF RESULTS}

Respondents showed an almost fifty/fifty split between the categories high and low social distance. Only two of the respondents $(N=108)$ fell into the client population category indicating work with minorities. Both of these respondents were in the high social distance category, the cell presumably indicating a higher degree of minority prejudice. The cell indicating low social distance and work with minority clients had zero respondents.

Since one of the respondents identified himself/herself as a minority it is possible the scale attempting to isolate the independent variable, social distance, does not in fact do so. If a respondent neither lived with nor near minorities, had no minority friends or did not work with minority clients, he/she could fall into a high social distance category. Only $N=108$ out of a total survey response of $N=115$ answered the social distance and client population questions. It is possible the minority respondents did not answer these questions. It is also possible minority social workers do not work with minority clients for the same reasons mentioned previously regarding the low minority numbers within the Portland metropolitan population. 
TABLE VII-A

Prejudice in Social Work Practice

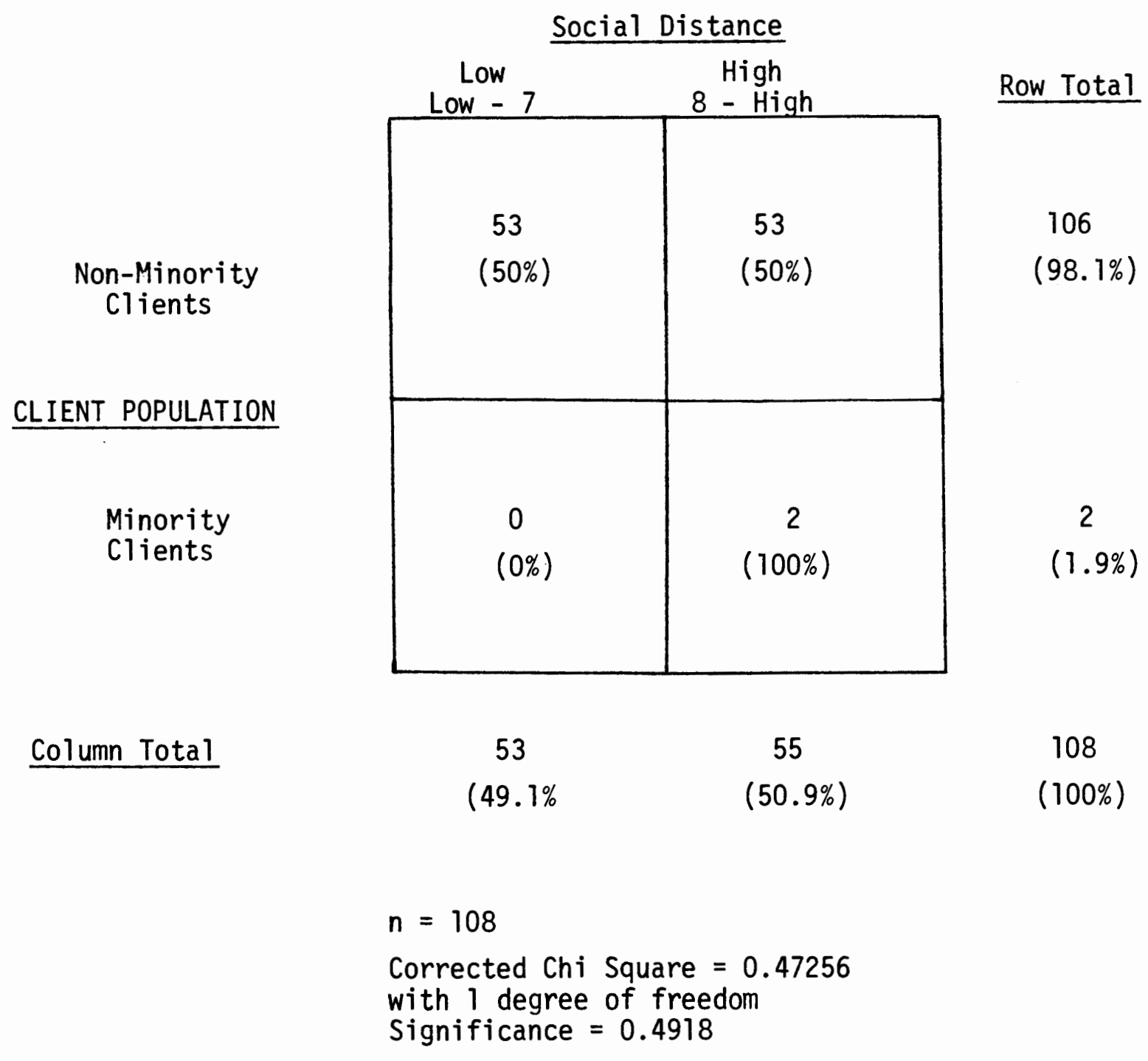


There is another possible explanation for the high social distance scores of respondents indicating work with minority clients. If a respondent marked "often" as a response to two of the three questions comprising the social distance scale (a combined score of 4) and "seldom" as a response to the remaining question (a score of 4 ), the total score would be 8 . This respondent, by indicating he/she seldom has contact with minority clients yet often socializes or lives near minority clients would still fall into the high social distance category. This could be reflective of a situation in which either the respondent had no choice of working with minorities or prejudice. Therefore, there are not enough distinguishing questions in this scale to measure social distance.

In analyzing the cross-tabulation comparing social distance with client population, it became apparent that virtually all respondents identified their clients in something other than racial/ethnic characteristics. That only two respondents indicated work with minority clients and these respondents were also high in social distance raises questions about the validity of the instrument. Questions regarding the validity of the instrument make it difficult to draw conclusions regarding this hypothesis. However, there are some interesting questions arising from this study.

Why, given a list of minority categories (admittedly, a non-mutually exclusive list), did almost all respondents identify their clients in other than racial/ethnic terms?

While one explanation may be that it is due to the lack of minorities in the Portland area, another equally plausible explanation may be that it is a result of workers' lack of knowledge of minorityrelevant issues. 


\section{E. SUMMARY AND RECOMMENDATIONS}

While one explanation for low alumni minority client contact may be that alumni simply do not have an opportunity to work with minority clients, a factor over which the School of Social Work has no control, an equally likely explanation for this may be that these graduates are less sensitive to minority issues due to lack of knowledge, i.e., curriculum content and minority student contact. Like 0liver, we can question whether or not the School of Social Work is providing the contact and minority-relevant knowledge needed to prepare alumni for working with minority clients.

We feel the results of this study bear further scrutiny in the context of 0liver's statement that it is the responsibility of the school's chief administrator and policy setting bodies to establish a climate promoting incorporation of minority-relevant course content (1976, p. 106). 
VIII. Assessment of Alumni Burn-Out in Social Work Practice

\section{A. PROBLEM STATEMENT}

The phenomena of burn-out in social service organizations is an increasingly recognized problem. Social service professions often require the worker to interact intensely with a wide range of $\mathrm{clients}$ for prolonged periods of time. These potent professional relationships may result in strong emotional reactions and therefore can be extremely stressful to the staff member. As evidenced in the literature, there has been little research involving the stress-related variables producing burn-out in the social service arena. As a result, professionals involved in social service do not have access to information and training to help neutralize the effects of burn-out. When awareness of stress experienced is not recognized or adequately dealt with, burn-out may be the result.

The problem of burn-out is addressed in the alumni survey by questions \#55-\#59. The questions are an attempt to determine to what extent the graduates of the Portland State University School of Social Work experience the effects of burn-out. This holds strong implications as to the inclusion of burn-out information in the curriculum at the School of Social Work to facilitate increased awareness and acknowledgement of burn-out by professional MSW's entering the social service field.

\section{B. LITERATURE REVIEW}

Empirical research studying the variables influencing burn-out and the actual effects of burn-out is relatively new and there is not much literature in this area. However, it is important to review 
several formal definitions of burn-out to gain a common understanding of the concept as it relates to the questions in the alumni survey.

Freudenberger defines burn-out as a wearing out, exhaustion, or failure resulting from excessive demands made on energy, strength, or resources (1977).

Michael R. Daly embellishes this definition by taking into account specific stressors related to a particular job situation. Accordingly, burn-out would be defined as "a reaction to job-related stress that varies in nature with intensity and duration of the stress itself" $(1979$, p. 375).

Christina Maslach, Ph.D., University of California at Berkeley, conceptualizes burn-out as a dynamic process and as a "reaction to jobrelated stress that results in the worker's becoming emotionally detached from $\mathrm{clients,} \mathrm{treating} \mathrm{clients}$ in a de-humanizing way, and becoming less effective on the job" (1979, p. 16). Maslach identifies various stages in the development of burn-out, characterized by typical responses by the staff member. For example, the worker minimizes his or her involvement with clients by keeping physically distant from them or by sharply curtailing the interviews (1977).

To date, the most formal research on burn-out has been operationalized by Christina Maslach and Ayala Pines. Preliminary studies were done from 1973-75 involving samples from over 200 psychiatric nurses, poverty lawyers, social workers, prison personnel and child-care workers. Initial results indicated that, "the incidence of burn-out is often very high in health and social service professions and is a major factor in low worker morale, absenteeism, high job turnover and other job indexes of job stress" (1978, p. 233). The syndrome of burn-out is manifested 
in physical and emotional exhaustion resulting in negative self-concept, negative job attitudes and an increased loss of concern and feelings for clients.

\section{METHODOLOGY}

A formal questionnaire was developed by Maslach and Pines and data was collected involving 76 staff members from a number of different mental health institutions in the San Francisco Bay Area. The questionnaire addressed (1) institutional variables, (2) personal variables, and (3) the effects of burn-out. Institutional variables included such dynamics as staff-patient ratio, characteristics of work relationships, and the work schedule. Personal variables included the degree of formal education of the staff members, sense of success and control, job attitudes and relationships with clients. Results of burn-out dealt with the stress of physical exhaustion and emotional distance.

To include the entire burn-out questionnaire was well beyond the scope and space limitations of the alumni survey. Therefore, five questions were chosen from Maslach's questionnaire. Three questions relate to the effects of burn-out and two questions explore empathy; the worker's relationship with the client. All five questions measure both frequency (how often) and depth (how strong). Therefore, there are ten responses in total for each respondent. For example, Question 55 is, "I feel (felt) personally involved with my client's problems." The respondent answers according to how often (ranges from a numerical value of 1 which represents daily, through 7 which represents yearly). The respondent is also asked to respond to depth with a range of 1 (very 
strong) through 5 (mildly).

Two index scores will be computed in the following manner. A total burn-out score will be obtained from multiplying the two measurements of each question (frequency and depth), then adding the multiplication results of all three burn-out questions, thereby computing a "totburn" score. Scores will range from 0 through 115. The lower the score, the more the effects of burn-out. The burn-out scores will be categorized into two divisions: high and low. High totburn scores are from the lowest score through 46 , low burn-out is from 47 through the highest score.

A second index score will be obtained for empathy in the same manner as the totburn index using the two questions related to the worker-client relationship. "Totempth" scores will range from 0 to 70 . The lower the score, the more feelings of empathy in the worker-client relationship on the part of the worker. As with totburn, empathy index scores will be defined as either high or low. High empathy scores are from the lowest score through a score of 13, low empathy scores range from 14 through the highest score.

Specific research questions looked at possible relationships between the dependent variables, burn-out and empathy, and the independent variables such as the number of hours employed per week, client population, job setting, sex, age, marital status and family composition. Additionally, a correlation was done to determine the extent of the relationship between totburn scores and totempth scores. 


\section{ANALYSIS OF RESULTS}

The total burn-out index score, from hereon referred to as totburn, had a possible range of $0-115$. The lower the score, the greater the effects of burn-out. The actual range was 99 , the smallest measurement being 6 , the largest measurement being 105 . The mean, or average, totburn score was 46 . The mode, or most frequent measurement, was 40 with five respondents having this score. The median, a number chosen so that half the measurements lie below it, half above, was 45 . High burn-out is categorized from the lowest score through 46 , low burn-out is from 47 to the highest score. Seventy-three of the total 115 respondents had high burn-out scores, or $63.5 \%$ of the total. Forty-two obtained lower burn-out scores, or $36.5 \%$ of the total.

The total empathy index score, from hereon referred to as totempth, had a possible range of $0-70$. Feelings of empathy increase as the score decreases, therefore the lower the score, the more feelings of empathy in the worker-client relationship. The actual range was 32 . The smallest measurement was 2 , the largest measurement was 34 . The mean totempth score was 13 , the mode was 8 with ten people having that score, and the median was 10. High empathy is categorized from the lowest score to 13 , low empathy from 14 through the highest score. of the 115 responses, 80 fell into the high empathy grouping which represents $69.6 \%$ of the total. Thirty-five responses indicated low empathy, or $30.4 \%$ of the total.

It is interesting with regards to a totempth score, that the highest score obtained was 34 out of a possible high of 70 . The lower scores are associated with higher degrees of empathy, indicating that all 
the MSW's responding had at least a moderate degree of empathy in the worker-client relationship. A large majority (almost $70 \%$ ) of the respondents were grouped into the high empathy categorization. The range was relatively small, signifying less variability among the totempth measurements. The mean score of 13 represents a relatively high degree of empathy.

The majority of responses $(63.5 \%)$ fell into the high burn-out grouping, indicating that these MSW respondents experienced some effects of burn-out. However, the range was higher for burn-out than for empathy, meaning there was more variability among the respondents. Out of a possible high score of 115, the highest score obtained was 105, the lowest 6 . A mean score of 46 indicates a moderate degree of the effects of burn-out.

A Pearson Product-Moment Correlation Coefficient $(r)$ measures the strength of the linear relationship between two variables measured on an interval or ratio scale. The correlation coefficient was determined to be .21 when comparing totempth with totburn. This means there was a very low correlation between the two index measurements.

In an attempt to determine the relationship, if any, between the independent variable age, and the dependent variable, totempth, crosstabulation procedures were performed.

Age was grouped in the following manner: Low through age 35 was categorized as the lower age group, age 36 and above as the higher age group. Thirty-five years was the mean age of the total 115 MSW respondents.

Two by two cells were used comparing low and high age with low and 
high totempth scores. The Correlated Chi Square was 6.85319 with one degree of freedom. The alpha significance level was 0.0088 . The alpha level needs to be equal to or less than 0.05 in order for a meaningful difference to occur. A level of 0.0088 , therefore, signifies a meaningful difference of totempth scores by age.

of the total 115 responses, 56 (or $48.7 \%$ of the total) were in the low age grouping, 59 (or $51.3 \%$ of the total) in the higher age bracket. Thirty-two $(57.1 \%)$ of the younger people had a high totempth score, compared with $48(81.4 \%)$ of the higher age grouping having a high totempth score. Twenty-four (42.9\%) of the lower age grouping also had low totempth scores, with only $11(18.6 \%)$ of the higher ages having low totempth scores. (See Table VIII-A.)

These scores indicate that there is a meaningful difference in totempth scores by age, with the higher age categorization ( 36 years and above) having significantly higher empathy scores than respondents age 35 years or less. Therefore, the null hypothes is, that there is no difference between age and having a higher totempth score, would be rejected.

It may be that as a person with a Masters Degree in Social Work gets older, the more years of training one receives and skill level is enhanced; therefore the ability to be empathic with clients is increased.

An assumption would be that people attempt to obtain increasingly more satisfying jobs in social work with the passage of time. Such considerations would be salary, job setting, client population and other job activities. Therefore, if an MSW is enjoying the job more, especially considering the clients one works with, it may facilitate 
TABLE VIII-A

TOTEMPTH AND AGE

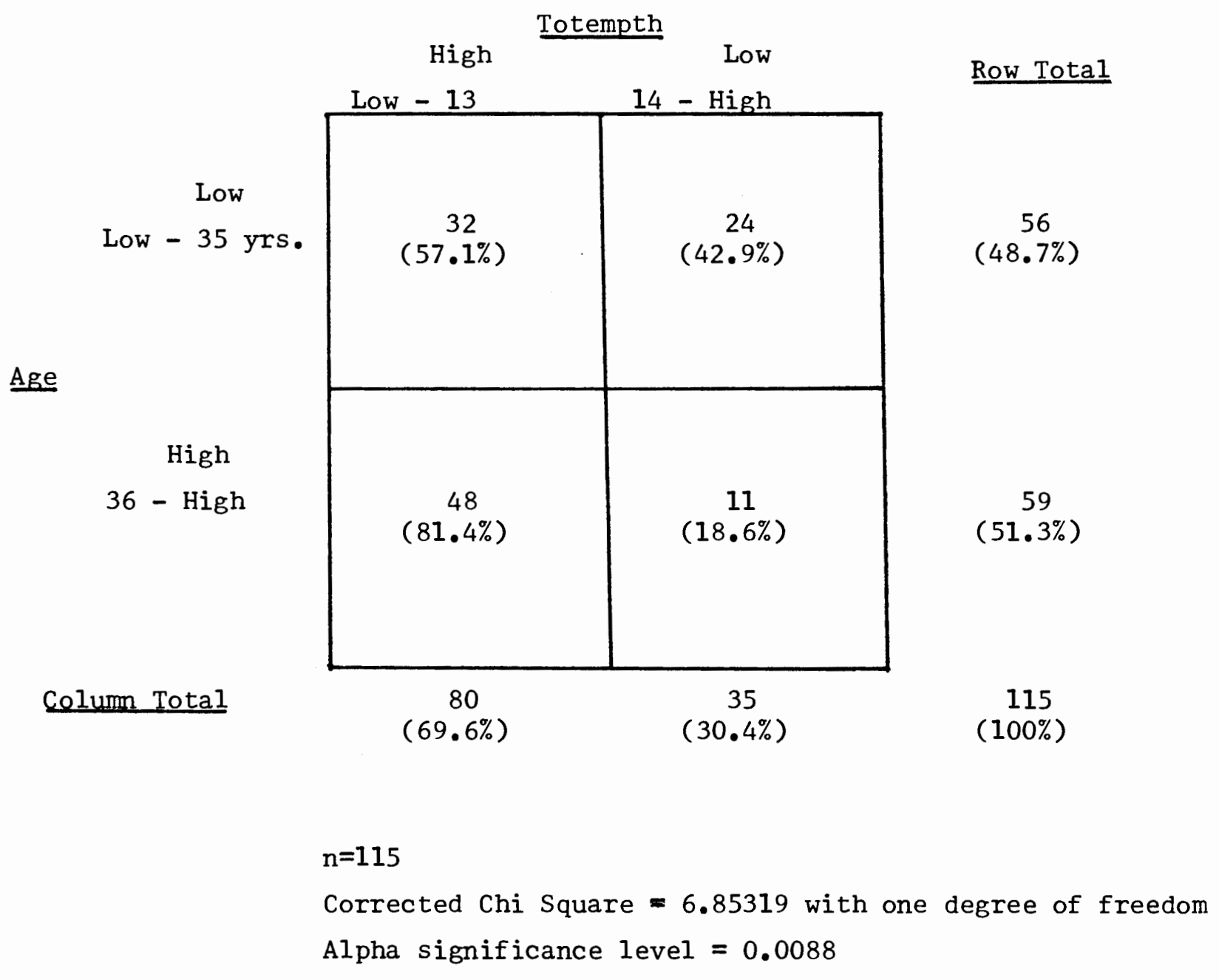


greater empathy in the worker-client relationship. Additionally, an MSW may specialize with a particular client population and the ability to be empathic may increase. General life experience and personal life situations, such as marital status and family composition, may also have an impact.

With regards to a relationship between age and totburn scores, no significant difference was found. The Corrected Chi Square was 2.34506 with one degree of freedom. The alpha level was 0.1257. As with totempth, 56 responses $(48.7 \%)$ were in the low age category, $59(51.3 \%)$ were in the higher age group. Of the low age group, $40(71.4 \%)$ responded with a higher totburn score, $16(28.6 \%)$ with a lower totburn score. Within the higher age group, $33(55.9 \%)$ had high totburn scores, $26(44.1 \%)$ had low totburn scores. Therefore, the majority of the young age group also had a higher percentage (71.4\%) of high totburn scores compared with $55.9 \%$ of the older age group having high totburn scores.

The number of hours per week an MSW worked was another independent variable explored to determine if any relationship existed with either totburn or totempth scores.

Hours per week worked were categorized into two groupings: those respondents working 20 hours a week or less and those working 21 hours a week or more.

Two by two cells were used comparing less than or equal to 20 hours a week and more than or equal to 21 hours a week with low and high totburn scores. The Corrected Chi Square was 11.40076 with one degree of freedom. The alpha significance level was 0.0007 , far below the 0.05 level which indicates a meaningful difference. 
of the 115 responses, 73 or $63.5 \%$ had high totburn scores, 42 or $36.5 \%$ had low totburn scores. Eighty-three $(72.2 \%)$ of the total number of respondents worked 20 hours a week and less, $32(27.8 \%)$ worked 21 hours a week and more. Of the less number of hours worked group, 61 (73.5\%) had high totburn scores as compared with only $12(37.5 \%)$ of the people working more hours. Twenty-two $(26.5 \%)$ of the 20 hours and under group had low burn-out compared with $20(62.5 \%)$ of the higher number of hours people. (See Table VIII-B.)

These scores indicate that there is a meaningful difference in having a high or low totburn score by number of hours worked per week. The people working 20 hours a week and under had significantly higher totburn scores than MSW's working more hours. Therefore, the null hypothes is would be rejected.

It was a surprising result that the MSW's who worked less hours a week evidenced more burn-out than those working more. This supports, therefore, that direct contact with clients is only one of the factors involved in burn-out. It may be that the part-time people receive less staff contact, perhaps less staff support than the individuals working full-time. Usually part-time employees receive less employee benefits, such as vacation time, sick leave, insurance, than the full-time people. The part-time MSW's may have less impact on the decision-making process regarding agency policies and activities than the full-time staff.

No significant difference was found with regards to a relationship between number of hours worked and having a high or low totempth score. The Corrected Chi Square was 0.11839 with one degree of freedom and an alpha significance level of 0.7308 . Eighty or $69.6 \%$ of the total 
TABLE VIII-B

TOTBURN AND NUMBER OF HOURS WORKED PER WEEK

rs worked $r$ week
Column Total

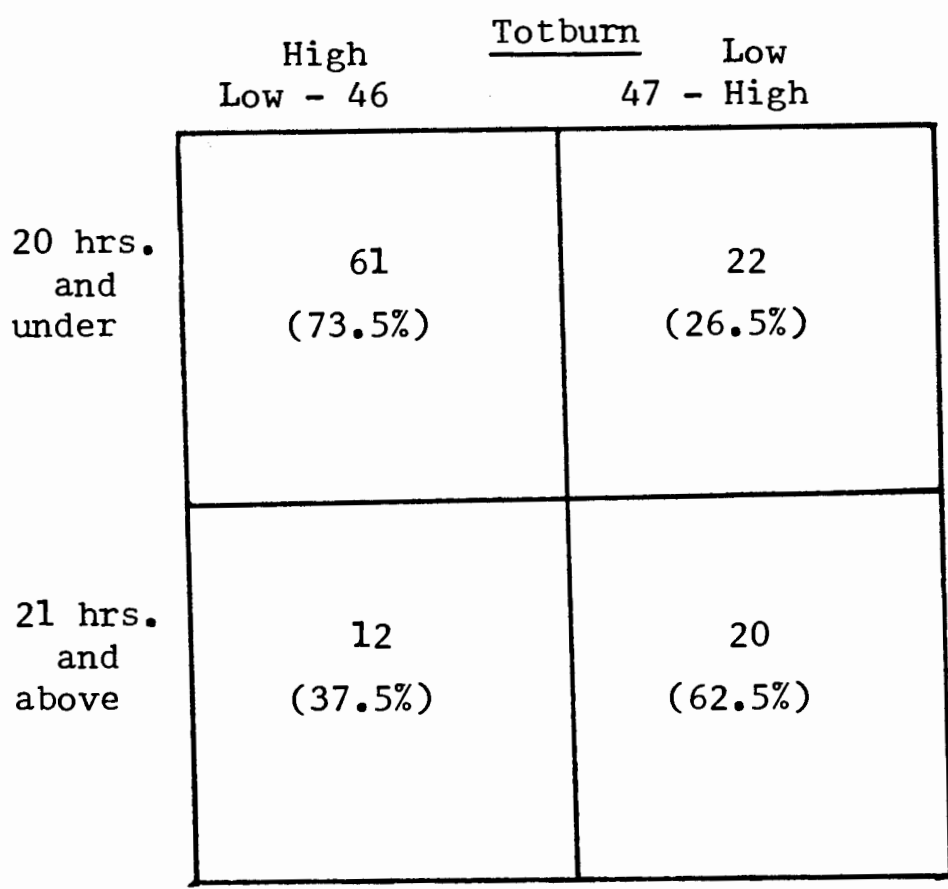

73

$(63.5 \%)$

42

115

$(100 \%)$

$\mathrm{n}=115$

Corrected Chi Square $=11.40076$ with one degree of freedom Alpha significance level $=0.0007$ 
respondents indicated high totempth, $35(30.4 \%)$ obtained low totempth scores. Fifty-nine (71.1\%) of the part-time people had high totempth, $21(65.6 \%)$ of the full-time also had high totempth scores. Twenty-four (28.9\%) of the part-time individuals had low totempth scores with 11 (34.4\%) of the full-time MSW's having low totempth scores.

Other independent variables were explored to determine possible relationships with totburn and totempth scores. These included sex, job setting, client population, marital status, and family composition (having children or not). No significant relationships were found.

Job settings looked at included services to children, mental health, services to the handicapped, public welfare, drug and alcohol abuse programs, private practice, corrections and courts and residential institutions. Client populations explored were children, adolescents, and the physically and emotionally handicapped. MSW's who had worked in social services but currently were out of the field were also reviewed.

Although no significant relationship was found, interesting results occurred when comparing people involved with drug and alcohol abuse programs with the private practice group. A total of only 11 people fell into these two job settings, therefore a Fisher Exact Test was used instead of a Corrected Chi Square. The Fisher Exact Test was 0.27879 . Of the 11 responses, $3(27.3 \%)$ were in drug and alcohol abuse, $8(72.7 \%)$ in private practice. $66.7 \%$ of the drug and alcohol abuse MSW's had high totburn scores as compared with only $25 \%$ of the private practice MSW's having high totburn scores. $33.3 \%$ of the alcohol and drug workers had low totburn scores and the majority (75\%) of the private practice individuals had low totburn scores. (See Table VIII-C.) 
TABLE VIII-C

TOTBURN AND JOB SETTING

b Setting

\begin{tabular}{|c|c|c|c|}
\hline & $\begin{array}{c}\text { High } \\
\text { Low }-46\end{array}$ & $\frac{\mathrm{mn}}{47-\mathrm{High}}$ & Row Total \\
\hline $\begin{array}{c}\text { Alcohol } \\
\text { and } \\
\text { Drug } \\
\text { Abuse }\end{array}$ & $\begin{array}{c}2 \\
(66.7 \%)\end{array}$ & $\begin{array}{c}1 \\
(33.3 \%)\end{array}$ & $\begin{array}{c}3 \\
(27.3 \%)\end{array}$ \\
\hline $\begin{array}{l}\text { Private } \\
\text { Practice }\end{array}$ & $\begin{array}{c}2 \\
(25 \%)\end{array}$ & $\begin{array}{c}6 \\
(75 \%)\end{array}$ & $\begin{array}{c}8 \\
(72.7 \%)\end{array}$ \\
\hline tal & $\begin{array}{c}4 \\
(36.4 \%)\end{array}$ & $\begin{array}{c}7 \\
(63.6 \%)\end{array}$ & $\begin{array}{c}11 \\
(100 \%)\end{array}$ \\
\hline
\end{tabular}

$\mathrm{n}=11$

Fisher Exact Test $=0.27879$ 
The exact opposite results were obtained when comparing these two job settings with totempth scores. Seventy-five percent of the private practice people had high totempth scores, only $33.3 \%$ of the drug and alcohol abuse individuals had high totempth. Twenty-five percent of the private practice MSW's had low totempth scores compared with the majority, $66.7 \%$ of the drug and alcohol abuse people having a low totempth score. (See Table VIII-D.)

\section{E. SUMMARY AND RECOMMENDATIONS}

It becomes evident that the majority of the MSW's responding to the alumni survey questionnaire have experienced some effects of burn-out working in the social service arena. $63.5 \%$ of the total number of respondents obtained high totburn scores. This suggests the importance of having some awareness and knowledge with regards to the effects of burn-out for individuals entering the human services field. This could be included in the School of Social Work curriculum. Research involving the phenomenon of burn-out is relatively new, therefore open to more in-depth studies regarding this subject.

The number of hours worked per week was found to have a relationship with obtaining a high totburn score. The majority (73.5\%) of individuals working 20 hours a week or less had high totburn scores. Of the people working 20 hours a week or more, on $7 y 37.5 \%$ had high totburn scores. This is important in view of the fact that the majority of the MSW's responding $(72.2 \%)$ work 20 hours a week or less in a social work position. Possible influencing factors may be staff support, employee benefits and impact on the decision-making process within the agency. It would 
TABLE VIII-D

TOTEMPTH AND JOB SETTING

b setting

Totempth

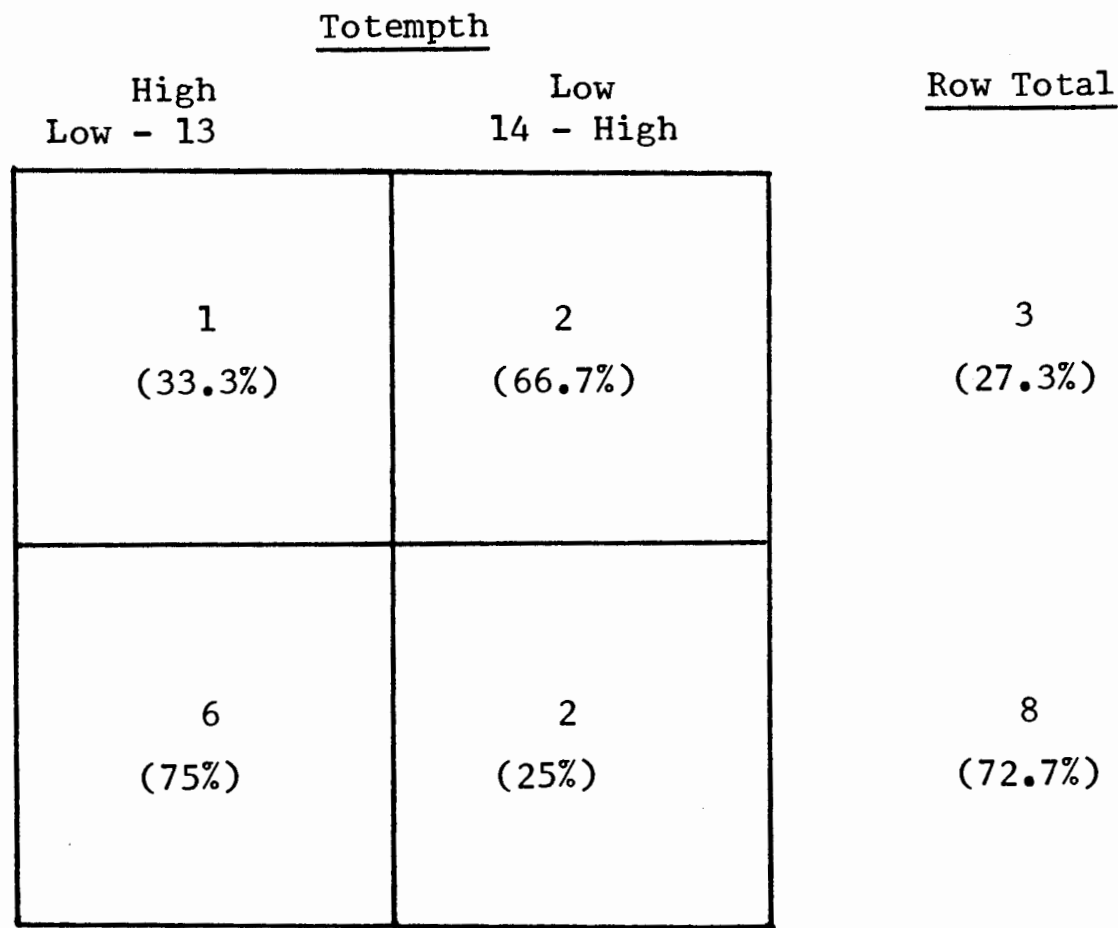

Jolum Total

Private

Practice
7

$(63.6 \%)$

4

$(36.4 \%)$
11

$(100 \%)$

$\mathrm{n}=11$

Fisher Exact Test $=0.27879$ 
be interesting to further explore the other factors influencing this finding.

The ability to be empathic in the worker-client relationship was associated with the independent variable, age. $81.4 \%$ of the MSW's age 35 or above had high totempth scores. Only $57.1 \%$ of the younger MSW's had high totempth scores. It would seem feasible to use the MSW's who have been in the field longer as possible resources for training, knowledge, increased skill ability and workshops. Further research is necessary to explore other possible variables involved with this finding such as job setting, client population and personal life situations. One large drawback of the alumni survey was the smal1 number of respondents. In many of the job setting cross-tabulations, the cells came out zero or very sma11, making a statement about meaningful differences impossible, such as the differences between private practice MSW's and alcohol and drug abuse MSW's. It is recommended that further studies regarding the independent variables possibly related to burnout, such as job setting, marital status, family composition and client population be done with a larger sample size. 


\section{Assessment of Alumni Social Welfare Policy Attitudes}

\section{A. PROBLEM STATEMENT AND LITERATURE REVIEW}

Questions 65 through 70 represent an index which is intended to assess the attitudes of social workers regarding social welfare policy. A definition of social welfare policy is derived from several sources. Kahn (1979, p. 8) and Meenaghan and Washington (1980, p. 15) define policy as a decision-making process by which a core group of values and principles concerning the individual and society are translated into specific programs and services. Gilbert and Specht define social welfare as "that patterning of relationships which developes in society to carry out mutual support functions" (1974, p. 5). Thus, when examining attitudes about social welfare policy, we are looking not only at particular service delivery systems, but also at the fundamental beliefs and values which underly that system of mutual support.

The index attempts to measure these attitudes by placing a respondent on a continuum ranging from more to less in favor of a deficit system of welfare provision. The debate between a deficit or non-deficit delivery system is seen as a central issue in the field of social welfare policy. Policy decisions based on a deficit concept translate into in-kind services, less-eligibility criteria, means-tests, categorical aid, and the like. A non-deficit conception of welfare, on the other hand, translates into universally available, non-categorical services, cash grants, and guaranteed minimum income levels.

The crucial point is that this deficit/non-deficit dichotomy represents a major value discrepancy as well. Deficit-based policy decisions imply that social problems exist primarily with the individual; 
so that services should be provided in a safety-net, temporary manner until the individual again can assume responsibility for him/herself. To the contrary, a non-deficit system views the individual as existing in an environment which by definition, and inevitably, causes problems; so that services are perceived to be universally-needed and are the collective responsibility of society.

Piven and Cloward (1977) and Galper (1975) develop strong arguments emphasizing the political nature of social welfare issues. To the extent that policy is based on a deficit view of welfare, the services and programs which result serve to maintain the status quo. Such programs are conceived to be meliorative; rescue the worthy individual by helping $\mathrm{him} / \mathrm{her}$ to again resume individual responsibility to function in the capitalist economy. By contrast, a non-deficit policy questions the application of marketplace criteria to human needs, and argues for structural changes away from individualistic capitalism toward a more collective socialism. In this sense, then, the index measures not only policy attitudes (deficit to non-deficit) but also political beliefs (conservative to radical).

There are available in the literature some existing scales which propose to measure attitudes about welfare, for example: Feagin (1979); Robinson, Rusk, and Head (1968); Robinson and Shaver (1973); and Wyers (1977). However, it was decided that these scales could not adequately discriminate the variance of attitudes which might exist among social workers. The existing scales measure attitudes of the general population, not those of a highly selective group of individuals, i.e., masters degree social workers. It is assumed that the field of social welfare 
policy is almost the exclusive territory of social workers. Therefore, it can be assumed, also, that social workers generally will have more liberal views concerning welfare than the general public. This is not to say that social workers as a group are perceived to be in agreement about welfare policy. To the contrary, some variance was anticipated, but to note this possible variance it was determined to make statements of a more radical nature (i.e., ones that were heavily weighted to nondeficit criteria).

\section{B. METHODOLOGY}

Each of the six questions that make up the index allows a five point Likert response, ranging from a score of (1) for strongly disagree to (5) for strongly agree. By adding the responses to all six questions a cumulative score can be obtained. In all questions the radical response corresponded to strongly agree (or a score of five). The exception was Question \#66 in which the radical response was strongly disagree (or a score of one). During scoring the response to \#66 was reversed, so that the cumulative score for the index could range from very conservative (a score of six) to very radical (a score of thirty).

Face validity provided the primary criterion for inclusion of each statement of the index. Ideally index construction would also address such criterion as unidimensionality and variance among index items. Selection of items to be included, then, would be based on biand multi-variant analysis of items. To further refine the instrument, scale construction could have been undertaken. A scale differs from an index by attempting to account for different intensities of each item. 
Construction of a Bogardus, Thurston, or Guttman-type scale is a fairly time-consuming and tedious process (Babbie, 1973, pp. 254-278). Suffice it to say that, given time constraints and the objectives of this study, such sophistication was neither indicated nor attempted. Therefore, the index rests primarily on face validity. Reliance on this criterion alone is an issue that will be considered in a later section where the data from the index is analyzed.

The first research question to be asked, then, is whether the index appears to be a reasonably good, composite measure of social welfare policy attitudes. Other questions to be addressed will deal with correlations between the index score and other content areas of the questionnaire such as age, sex, curriculum track and so on. The purpose will be to discover relationships or trends between the dependent variable, social welfare attitudes, and these other independent variables.

\section{ANALYSIS OF RESULTS}

Part 1 - The Instrument

Earlier, it was noted that face validity was the only test of validity applied to the construction of this index. This lack of further validation certainly can be construed as a weakness of the instrument, since it may not measure what was intended. In favor of the instrument's validity, however, is the following analysis of the responses to each question, which seems to indicate that the scale is internally valid, although this did not result entirely by design.

In constructing the index, there was an attempt to duplicate a Guttman scaling technique by making each question succeedingly difficult 
to answer affirmatively. Hence the initial statement would gather a high proportion of agree (or strongly agree) responses. Each following statement would receive fewer agree responses. Thus, if (as in the case of this index) the agree statements were the radical responses, each index item was intended to be progressively more radical (with progressively fewer responses in agreement).

Table IX-A demonstrates that this pattern did not result. For analysis purposes there are three response categories (i.e., agree and strongly agree were collapsed together, as were disagree and strongly disagree; unsure/it depends was maintained as a single category; the percentage is based on actual responses--missing data is not included).

\section{TABLE IX-A}

\section{DISTRIBUTION OF ITEM RESPONSE}

$\begin{array}{lccrr} & \text { Radical } & \text { Unsure } & \text { Conservative } \\ \text { Q. } 65 & 88(76.5 \%) & 21(18.3 \%) & 6(5.2 \%) \\ \text { Q. } 66 & 31(27.4 \%) & 48(42.5 \%) & 34(30.1 \%) \\ \text { Q. } 67 & 29(25.7 \%) & 35(31.0 \%) & 49(43.3 \%) \\ \text { Q. } 68 & 70(61.9 \%) & 22(19.5 \%) & 21(18.6 \%) \\ \text { Q. } 69 & 72(64.9 \%) & 22(19.8 \%) & 17(15.3 \%) \\ \text { Q. } 70 & 73(65.2 \%) & 22(19.6 \%) & 17(15.3 \%)\end{array}$

The pattern that does develop, though, seems to demonstrate internal validity. Question 65 received the highest radical response rate (over $3 / 4$ responding in favor of the radical answer). Questions 68,69 and 70 show almost identical responses across categories, and still a fairly high radical response rate (almost $2 / 3$ in favor of the radical answer). Questions 66 and 67 also have similar responses across categories. These 
two questions received the fewest radical responses (1ess than $1 / 3$, making it the most difficult with which to agree).

Though unintended, the pattern described above appears to be related to the content area of the questions. The more concrete the statement concerning welfare policy, the less likely were respondents to be radical. Conversely, the more theoretical (and non-specific) the statement the easier (more likely) it was to agree. Question 65 is the most theoretical. It states in effect that the existence of a welfare system derives from society's responsibility to the individual. It is hard to imagine too many social workers dissenting from that view, and indeed only $5.2 \%$ disagreed. But the statement is intentionally vague. It does not suggest how much responsibility society should take or what form the welfare system should take. Thus, it's easy to agree.

Questions 68,69 and 70 are not quite as easy to agree with. These three questions deal with more specific subject matter than \#65. Question 68 deals with redistribution of income; 69 with a guaranteed income; and 70 with structural changes in the society. Nevertheless, these concepts remain vague and theoretical, which is to say imprecise and open to a wide range of interpretation.

Questions 66 and 67 are much more concrete and specific (and less theoretical). One suggests linking maximum welfare benefits to potential minimum wage earning; the other suggests abolishing in-kind services in favor of cash grants. The fewest radical responses were received on these two questions. They were the most difficult with which to agree. The point is that it appears that the respondents found it fairly easy to agree with radical social welfare policy statements which were 
theoretical (general) and fairly non-specific. The questions dealing with more concrete proposals--wherein policy theory was specified (put into action)--were not as easy to answer. Most respondents disagreed with or were unsure about concrete examples of radical social welfare policy.

The questions, then, seem related and internally valid, since there is a pattern of higher favorable/affirmative response to the more theoretical statements. The implication seems to be that social workers (those responding to this survey) agree theoretically with radicallystated social welfare policy, but are less likely to agree when those radical policies are specified in concrete proposals/terms.

\section{Part 2 - Correlations}

By cumulating each item score, a single variable, social policy attitude, was computed from the index. This independent variable was cross-tabulated with several dependent variables to determine if social policy attitude could be predicted from or was related to the other variables. For the purposes of analysis, it was decided to use two-bytwo tables. The computed variable was divided into two categories, conservative and radical. The former category included all respondents scoring fifteen or less on the index; the latter included scores of sixteen or greater. (The range of possible scores was from 6 to 30 . The median fell within the score of 15 , so this score was chosen to divide the variable into the two categories.)

The variable, social policy attitude, was then cross-tabulated (by SPSS procedure) with the following seven dependent variables, each 
of which was divided into two categories:

1) date degree awarded - earlier graduates were determined to be those receiving degrees in the period from 1971 through 1975; recent graduates were those receiving degrees since 1975 .

2) curriculum track - either direct service or planning.

3) social service experience prior to graduate school - those with less than six years experience, and those with six years or more. The median fell roughly at six years.

4) age at time degree was awarded - the median fell within 32 years; the two categories chosen were those who were younger than 32 , and those who were 32 or older.

5) $\underline{\text { sex }}$ - male or female

6) age - the median fell at 35 ; the two categories were those younger than 35 , and those 35 or older.

7) race/ethnic group - non-white and white.

In cross-tabular analysis, the intent is to discover associations between the two variables. With each of the seven dependent variables, two hypotheses could be derived:

$\mathrm{H}_{1}$ : a dependence exists between the independent variable, social policy attitude, and the particular dependent variable being tested.

$\mathrm{H}_{0}$ : the two variables are independent, i.e., not associated.

Chi square was used as the test statistic. At a Chi square significance of .05 or less (i.e., a confidence level of $95 \%$ ) the null hypothes is was to be rejected; thus accepting the existence of an association or dependence between the two variables. Where an association did exist the phi coefficient was used to determine the relative strength of 
association. A phi of zero indicates no association. As the coefficient approaches the whole number one, the indicated association becomes stronger.

Associations were found with three of the dependent variables tested. The first, with "date degree awarded," was extremely strong. The chi square at one degree of freedom to four decimal points was zero. The phi was .42. The association, however, was not what might be expected. It was anticipated that more recent graduates would be more radical regarding social policy, mainly by virtue of having recently studied this material in graduate school. The opposite appears to be the case. Of recent graduates responding, only $28 \%(20)$ were ranked radically; while $72 \%$ (52) were ranked conservatively. Earlier graduates responded at rates of $71 \%$ (30) radical, and $29 \%$ (12) conservative. The interpretation is that more recent graduates are more likely to be rated conservatively by the index, while those respondents who graduated between five and ten years ago are more likely to be rated radically.

Several possible explanations are suggested. First the instrument may be at fault. Given questions raised earlier about validity it may be that the index does not accurately measure the intended attitude. Of course, this could be the case throughout this crosstabular analysis.

Another possibility is that the curriculum of the school has changed over the years, so that more recently social policy has received less emphasis than during the earlier period between 1971 and 1975. At the same time, it may be that these results are reflective of a more conservative trend on the part of the population as a whole 
in recent years, a trend noted in the popular media, opinion polls, and in the most recent national elections.

A second association was noted between the independent variable and the dependent variable, "present age." Here, younger respondents appeared more likely to be conservative, $84 \%$ (16); while only $16 \%$ (3) were ranked radically. 01der respondents were about evenly divided between conservative $(51 \%$, or 49$)$ and radical $(49 \%$, or 47$)$. Chi square was computed at 5.815 with one degree of freedom, for a significance of .016. The phi of .25 is closer to one than was the phi of the previously discussed association with "date degree awarded." Thus, the association with "present age" is weaker than the preceding one. Perhaps this is because of the fairly even split in the older group between conservative and radical.

Typically, one might expect younger persons to rank more radically and older persons to rank more conservatively. The writer has no ready explanation for the tendency of younger respondents to be conservative. If there had been associations noted with the dependent variables, "age at time of degree" and "experience prior to graduate school" such that younger and less experienced respondents appeared more likely to be ranked conservatively, and older and more experienced respondents ranked more radically, one might begin to speculate about movement toward more radical policy attitudes as one gets older and has more experience in the field. The survey contained no inquiry regarding total number of years in the field. And neither of the two variables just mentioned showed any significant association when cross-tabulated with the independent variable. 
A third association was noted between social policy attitude and "curriculum track." With a chi square of 4.067 at one degree of freedom a significance level of .0437 was computed. The phi of .21 appears relatively weak, compared to the phi calculated for the crosstab with "date degree awarded." Those respondents in the planning track were more likely to be conservative (79\%, or 15$)$, while only $21 \%$ (4) were ranked radically. Direct service respondents were about evenly divided: conservative--50.5\% or 47 ; radical-- $49.5 \%$ or 46 .

Here, too, is an unexpected result. The writer anticipated that planning track respondents would have been more likely to be ranked radically by virtue of having concentrated their graduate education in skills relative to the implementation of human service programs, programs which derive from policy and politics. Perhaps the curriculum does not emphasize this material as the writer perceived. If it is assumed that most of the planning track respondents work in a planning position, one might speculate that there is a conservatizing effect as one works in the organizational and bureaucratic setting of such positions.

The cross-tabulations with "sex" showed no significant association with the independent variable. No association was found, either, with the dependent variable "race/ethnic group." No doubt this was largely due to the extremely small sample of only six non-white respondents.

\section{SUMMARY AND RECOMMENDATIONS}

The first research question to be addressed was whether the index could be considered a valid measure of attitudes regarding social policy. 
Reliance on face validity above was noted as a short-coming; however, the response pattern which developed seemed to indicate that the index had internal validity, as well, thus increasing confidence in it. The implication of the observed response pattern was that respondents were less likely to identify with radical social policy as statements about that policy became more concrete and specific. One conclusion may be that social policy is understood in fairly theoretical and general terms. The linkage between social policy theory and the enactment of that policy in specific programs and strategies may bear more scrutiny and emphasis in the curriculum.

Little can be said conclusively about what variables might be associated with social policy attitudes. There is some suggestion that age is a factor, so that an older respondent was more likely to hold radical attitudes. A trend (though not a firm correlation) was noted toward more radical attitudes on the part of those who were older when the MSW was earned. These two factors and the association between radical policy attitudes and graduation five to ten years ago suggest that there may be some further relationship between policy attitude and total years experience in the social services (a variable not addressed in the survey). Presumably, those who are presently older, who were older when the MSW was awarded, and who graduated more than five years ago have worked longer in the field. This is only a hunch at present but may indicate that the longer one is employed in social work the more one identifies with radical social policy.

Conversely, the predominance of conservative attitudes among presently younger respondents, among those who were younger when 
graduated, and among more recent graduates raises questions. Is this the result of a preponderance of conservative attitudes throughout the general population and particularly younger adults? Do the attitudes and values of social workers (specifically P.S.U. respondents) actually differ from the general population? Does the P.S.U. curriculum emphasize more traditional and conservative social policy? Do graduates actually tend to become more radical regarding social policy over time; or are the associations noted the result of attendance at P.S.U. at a particular time? These questions, raised by the present study, ought to be considered as subject matter for further research regarding the school, its curriculum, and its alumni. 


\section{Conclusions of the Survey}

One of the stated purposes of the Alumni Survey was to provide group members with practical research experience. Survey research was chosen as the specific means by which to gain that experience. Our survey was structured as descriptive research. The purpose was neither to explore a new area nor was it to discover cause-effect relationships; rather, we attempted to describe a particular population--the alumni of P.S.U. SSW of the past ten years.

We have attempted to explore some of the benefits and liabilities of survey research, and in the process have simulated not only the research process, but also the research setting. As stated in the beginning, it was assumed that the research process is not strictly a linear one. Indeed, we have found this to be true, and conclude that the researcher must be, in Michael Patton's words, "active-adaptivereactive" (1978). From the beginning it was clear that initiative for the survey would have to come from group members. As problems arose, it became the responsibility of group members to identify the problems and to devise effective new strategies.

It seems realistic to assume that any future professional research experienced by group members will come in a field agency setting, as part of a research (or evaluation) team/unit. In this sense, the alumni survey has provided experience with a task-group, dealing with such group dynamics issues as divisions of labor, agenda-setting, facilitation, deadlines, and even some budgeting.

In the process of describing the alumni of the past ten years, we have attempted to address relevant issues regarding the school and its 
relationship to its alumni. Perhaps our most basic recommendation would be that the school devise a systematic means of maintaining an accurate list of alumni and their current mailing addresses. This may be easier said than done; but without it, communication from the school to alumni, and the consequent feedback, is not likely to be effective. We can only speculate about how much more representative our data would have been if the mailing list had been more accurate. Too, we might lobby for financial support from the school for alumni survey research--not only because of the considerable expense of the present undertaking, but also because continuing alumni research could provide an invaluable evaluative tool for administrative decision-making.

Our examination of the linkage between the School of Social Work and its alumni has led us, inevitably, to the curriculum. In this area we have attempted, at least, to raise relevant questions and when possible to offer recommendations. One important suggestion was that the direct service and planning curriculum tracks are too separate, and ought to be more interrelated. Another suggestion was that professional burn-out material be made a part of curriculum content. The general lack of awareness by alumni of minority discrimination and prejudice tends to argue for more curriculum content, also. One caveat may be added--as with social welfare policy attitudes, one may have a theoretical but not a practical understanding of certain issues. Therefore, whatever content areas may be added to the curriculum, careful attention needs to be given to applying theory to practice.

Finally, we hope that alumni survey research by the School of Social Work does not end here. From the start of this project we have 
thought of it as a beginning step to a more continuous evaluation of the school by its alumni. If this practicum results in that feedback loop, then its second purpose will have been completed. 


\section{BIBLIOGRAPHY}

Allport, Gordon W. The Nature of Prejudice. Philippines: AddisonWesley Pub. Co., Inc., 1979.

Babbie, Earl R. Survey Research Methods. Belmont, California: Wadsworth Publishing Co., 1973.

Belon, C.S., and Gould, K.H. "Not Even Equals: Sex-Related Salary Inequities," Social Work 22 (June 1977): 466-71.

Brayfield, Arthur H.; Wells, Richard V.; and Strate, Marvin W. "Interrelationships Among Measures of Job Satisfaction and General

Satisfaction." Journal of Applied Psychology 41 (August 1957): 201-205.

Council on Social Work Education, Manual of Accrediting Standards for Graduate Professional Schools of Social Work.

Daly, Michael R. "Burn-Out: Smoldering Problem in Protective Services." Social Work 24 (September 1979): 375-379.

Encyclopedia of Social Work, 17th ed. S.V. "Profession of Social Work: Contemporary Characteristics," by Henry J. Meyer and Sheldon Siegel.

Feagin, Joe R. "America's Welfare Stereotypes." Social Science Quarterly 52 (March 1979): 921-933.

Figueira-McDonough, Josefine. "Discrimination in Social Work." Social Work 24 (March 1979): 214-23.

Freudenberger, Herbert J. "Burn-Out: Occupational Hazard of the Child Care Worker." Child Care Quarterly 6 (Summer, 1977): 90.

Galper, Jeffrey H. The Politics of Social Services. Englewood Cliffs, New Jersey: Prentice-Ha11, 1975.

Gilbert, Neil, and Specht, Harry. Dimensions of Social Welfare. Englewood Cliffs, New Jersey: Prentice-Ha11, 1974.

Jahoda, Marie, et al. Research Methods in Social Relations: With Especial Reference to Prejudice. New York: The Dryden Press, 1951.

Kahn, Alfred J. Social Policy and Social Services. New York: Random House, 1979.

Kasschau, P.L. "Age \& Race Discrimination Reported by Middle Aged \& 01der Persons." Social Forces 55 (March 1977): 728-42.

Knapman, S.K., "Sex Discrimination in Family Agencies." Social Work 22 (June 1977): 461-65. 
Larsen, John M. Jr., and Owens, W.A. Jr. "The Assignment of JobAttitude Items to Subscales." Journal of Applied Psychology 49 (June 1965): 172-181.

Locke, Edwin A.; Smith, Patricia Cain; Kenda11, Lorne M.; Hulin, Charles L.; and Miller, Anne M. "Convergent and Discriminant Validity for Areas and Methods of Rating Job Satisfaction." Journal of Applied Psychology 48 (October 1964): 313-319.

Mas1ach, Christina. "Burned-Out." Human Behavior 5 (September 1979): 16-22.

Maslach, Christina, and Collins, Gary R. "Burn-Out: The Hazard of Professional Helpers." Christianity Today 21 (April 1977): 12-14.

Maslach, Christina, and Pines, Ayala. "Characteristics of Staff BurnOut in Mental Helath Settings." Hospital and Community Psychiatry 29 (April 1978): 233-237.

Meenaghan, Thomas M., and Washington, Robert 0. Social Policy and Social Welfare. New York: The Free Press, 1980.

National Association of Social Workers. Code of Ethics of the National Association of Social Workers. Washington, D.C.: NASW, Inc., 1979.

01 iver, John. "A Pragmatic Model for Integrating Minority Content in Social Work Curriculum: Toward Developing an Alternative Incentive Network." Journal of Education for Social Work 15 (Spring 1979): 106-108.

Piven, Frances Fox, and Cloward, Richard D. Poor People's Movements: Why They Succeed, How They Fail. New York: Vintage Books, 1977.

Robinson, John P.; Rusk, Jerrold G.; and Head, Kendra B. Measures of Political Attitudes. Survey Research Center, Institute for Social Research, 1968.

Robinson, John P., and Shaver, Phillip R. Measures of Social Psychological Attitudes. Survey Research Center, Institute for Social Research, 1973.

Selltiz, Claire. Research Methods in Social Relations. New York: Holt, Rinehart and Winston, Inc., 1976.

Turner, Frances J. Social Work Treatment: Interlocking Theoretical Approaches. New York: The Free Press, 1979.

University of Tennessee. School of Social Work. Alumni Survey: 1979. 
Wherry, Robert J. "Factor Analysis of Morale Data: Reliability and

Validity." Personnel Psychology 11 (Spring 1958): 78-89.

Wyers, Norman L. "Belief, Policy, and Program: Changing Perspectives

in America." (Unpublished paper.) Portland State University, 1977. 
APPENDIX

THE QESTIONNAIRE

Portland State University

Schnol of Social Work

December, 1980

An alumni survey is being conducted at Portland State University School of Social Work. Your participation in completing the enclosed questionnaire is requested.

The survey has been developed by second year students, and in part will be used to meet research practicuum requirements. The findings also will be presented formally to the school's curriculum committee, which has expressed considerable interest in the survey. Two bound copies of the survey will be available later in the year at Portland State University library, for review by students and other interested persons.

The data collected will be used in aggregate form. All individual replies will be anonymous and confidential. By returning the questionnaire, you are granting permission to use the data for the purposes described above.

Of course, your participation is voluntary. Your response will increase the relevance of the survey. Your time in completing the questionnaire is appreciated. 
1. Since receiving your MSW, have you ever been employed as a social worker?

(1) yes

(2) (If no, describe job and title and skip to $q .17$.

2. What is your current employment status and hours/week worked? (Reply for major job if more than one held.)

(1) Employed full time in social work $\mathrm{hrs} / \mathrm{wk}$

(2) Employed part time in social work hrs/wk

(3) Not employed by choice

(4) Not employed but looking

(5) Employed but not in social work hrs/wk

(6) Other (Exp1ain)

If you checked 1 or 2 in 9.2 , please answer the following questions; otherwise (i.e. you are not currently employed in social work) skip to q. 10 .

3. List job title and describe your responsibilities

4. What is the setting in which you are currently employed? (Check the one category which is most appropriate.)
(01) Alcohol abuse
(02) -Aged
(03) Child guidance
(04) Child welfare
(05)-Co1lege-university
(06) Community action-poverty
(07) Community center-settlement house
(08) Community mental health
(09) Corrections
(10) Council planning
(11) Courts
(12) Drug abuse
(13) Family agency
(14) Handicapped

(15)

(16) Hospital, mental

(17) Minority groups

(18) Public welfare

(19) Residentia1 institution

(20) School

(21) Vocational rehab'n

(22) Youth service

(23) Private practice

(24) Other (Please specify 
5. What are the auspices of your current employment? (Check one.)

\section{(01) Public Title XX}

(02) Public Non-Title XX

(03) Private non profit

(04) Private profit
(05) Combined pub1ic/private

(06) Other (Please specifiy.)

6. Choose the five activities which occupy most of your time. Rank ord, them from 1 (most) to $\underline{5}$ (least).

(01)Direct service to individual clients

(02)Direct service to families

(03)Direct service to groups

(04)Acting as a client advocate

(05) Staff development and training

(06) Supervising other staff members

(07) Consulting with staff members

(08)Attending staff meetings

(09) Budgeting/financial planning

(10) Fund raising

(11) Developing new programs

(12)Writing (reports, articles, etc.)
(13)Planning/doing resea

(14) Consulting with othe agencies

(15) Meeting with communit groups

(16) Meeting with pub1ic officials

(17)Direct service to ca? givers (foster parent teachers, etc.)

(18) Other (Please specif:

7. What is your current yearly salary (at a full time rate)?

(01) Under $\$ 7,999$

(02) $\$ 8,000-8,999$

(03) $\$ 9,000-9,999$

(04) $\$ 10,000-11,999$
(05) $\$ 12,000-13,999$

(06) $\$ 14,000-15,999$

(07) $\$ 16,000-17,999$

(08) $\$ 18,000-19,999$
(09) $\$ 20,000-24,999$

(10) $\$ 25,000-29,999$

(11) $\$ 30,000$ and abovt

8. In which city and state is your current job located?

9. Is your current social work job the first job as a social worker that you held after receiving the MSW?

(01) Yes (If yes, please skip to Q. 1-.) (02) No

Please answer questions 10-16 only if your current job is NOT your first $j o b$ as a social worker since receiving your MSW.

10. What was your job title and what were the major responsibilities in your social work job?

11. Was your first post-MSW social work job a fulltime one? (01) Yes (02) No (If no, list hours per week.) 
12. What was the setting in which you were employed in your first post-MSW social work job? (Check the one category which is most appropriate.)
(01) Alcohol abuse
(02) Aged
(03) Child guidance
(04) Child welfare
(05) College-university
(06) Community action-poverty
(07) Community center-settlement house
(08) Community mental health
(09) Corrections
(10) Councel planning
(11) Courts
(12) Drug abuse
(13) Family agency

(14) Handicapped

(15) Health

(16) Hospital, mental

(17) Minority groups

(18) Public welfare

(19) Residential institution

(20)-Schoo1

(21) Vocational rehabilitatiol

(22) Youth service

(23) Private practice

(24) Other (P1ease specify.)

13. What were the auspices of your first post-MSW social work job?
(01) Public Title XX
(02) Public Non-Title XX
(03) Private non-profit
(04) Private profit

(05) Combined public/private

(06) Other (P1ease specify.)

14. Choose the five activities which occupied most of your time. Rank order them for $\underline{1}$ (most) to $\underline{5}$ (1east).

(01)Direct service-individual client

(02)Direct service-families

(03)Direct service-groups

(04)Acting as client advocate

(05) Staff development/training

(06) Supervising other staff

(07) Consulting with staff members

(08) Attending staff meetings

(09) Budgeting/financial planning

(10) Fudn raising

(11) Developing new programs

(12)Writing (reports, articles, etc.)
(13) Planning/doing research

(14) Consulting with other agencies

(15) Meeting with community groups

(16) Meeting with public officials

(17) Direct service to care givers (foster parents, teachers, etc.)

(18) Other (please specify.)

15. What was your starting salary at your first post-MSW social work job: (at a full time rate)?

$\begin{aligned}(01) & \text { Under } \$ 7,999 \\ -(02) & \$ 8,000-8,999 \\ -(03) & \$ 9,000-9.999 \\ -(04) & \$ 10,000=11,999\end{aligned}$

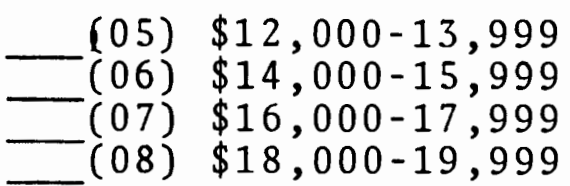

(09) $\$ 20,000-24,999$

(10) $\$ 25,000-29,999$

(11) $\$ 30,000$ \& above

16. In which city and state was your first post-MSW social work job? 
The following group of questions pertain to an evaluation of the Portland State University MSW curriculum.

sase evaluate the following curriculum areas and courses in terms of their helpfulness you. Circle your rating, with 5 being the highest rating and 1 being the lowest. not applicable) is to be circled if you did not take courses in that area.

CURRICULUM AREA

Field placements

Direct service core practice methods courses

Social planning/management (Comm. organ.) core courses

History of social work

Social policy

Interviewing skills laboratory

) Human behavior and social environment (Issues and persrectives) core courses

) Research practicum

Thesis

Core research courses

Statistics

Courses in general

Other courses taken as part of MSW program

Title:

Title:

Title:

\begin{tabular}{cccccc}
\multicolumn{5}{c}{ HEIPFULNESS } \\
HIgh & & & LOW \\
5 & 4 & 3 & 2 & 1 & NA \\
5 & 4 & 3 & 2 & 1 & NA \\
5 & 4 & 3 & 2 & 1 & NA \\
5 & 4 & 3 & 2 & 1 & NA \\
5 & 4 & 3 & 2 & 1 & NA \\
5 & 4 & 3 & 2 & 1 & NA \\
& & & & & \\
5 & 4 & 3 & 2 & 1 & NA \\
5 & 4 & 3 & 2 & 1 & NA \\
5 & 4 & 3 & 2 & 1 & NA \\
5 & 4 & 3 & 2 & 1 & NA \\
5 & 4 & 3 & 2 & 1 & NA \\
5 & 4 & 3 & 2 & 1 & NA \\
& & & & & \\
5 & 4 & 3 & 2 & 1 & NA \\
5 & 4 & 3 & 2 & 1 & NA \\
5 & 4 & 3 & 2 & 1 & NA
\end{tabular}

in two courses have been the most helpful?

?(Check approprlate reasons)

(2)

1) Knowledge gained

2) Skill(s) learned

3) Personal effect of instructor

4) Other (Please specify)

Why? (Check appropriate reasons)

(1) Knowledge gained

(2) Skill(s) learned

(3) Personal effect of instructor

(4) Other (Please specify)

in two courses have been the least helpful?

? (Check appropriate reasons)

1) Knowledge gained

2) Skill(s) learned

3) Personal effect of instructor

4) Other (Please specify)
(2)

Why? (Check appropriate reasons)

(1) Knowledge gained

(2) Skill (s) learned

(3) Personal effect of instructor

(4) Other (Please specify)

riew of your experience, what course material would you like to see added to curriculum? 
The following questions ask for some facts about you.

18. Do you prefer to work full time as opposed to part time?

(1) Yes

19. Have you received another degree since the MSW?

(1) Yes

(2) No

If yes, explain

20. In general, how satisfied are you with your PSU educational experience as preparation for your post MSW career?

(1) Very satisfied

(2) Quite satisfied

(3) Somewhat satisfied

(2) No

$-(2)-N o$

(4) Not very satisfied

(5) Not at all satisfied

21. The PSU Office of Continuing Education offers courses in social work to further professional interests and competence. If further education is of interest to you, please indicate what courses, workshops, etc. you would like to see offered.

22. If you are not currently enrolled in a doctoral program in social work (DSW or PhD), how interested are you in doing so in the future?

(1) Very interested

(2) Quite interested

(3) Somewhat interested
(4) Not very interested

(5) Not at all interested

23. If you have an interest in doctoral studies in social work, would you be interested in such a program at PSU if one were developed?

(1) Very interested

(2) Quite interested

(3) Somewhat interested
(4) Not very interested

(5) Not at a11 interested

24. As an alumnus, would you like further service from the school?
(1) Yes

(2) No 
25. If yes, what kind of service? (Check as many as are appropriate.)

(1) Job placement

(2) Certificate program in clinical practice

(3) Certificate program in social work management

(4) Workshops

(5) Summer institutes

(6) Other

26. Through which process did you enter the School of Social Work?

(1) Part time (If part time, for how many years?)

(2) Regular two year

27. What date did you enter the MSW program?

28. What date did you receive your degree?

29. In which method did you specialize in the School of Social Work?

(1) Social work treatment (Inlcudes casework/group work)

(2) Planning and management (Includes community organization)

If you were specializing in a concentration, which concentration was it?

(1) Community mental hea1th

(2) Program evaluation

(3) Native American

30. Did you work during the time you attended school?

(1) No

If yes, did you work:

31. What was the setting of your first year field instruction?

(Check the one category which is most appropriate.)

(01) Alcohol abuse

(02) Aged

(03) Child guidance

(04) Child welfare

(05) College-university

(06) Community action-poverty

(07) Community center-settlement house

(08) Community mental health

(09) Corrections

(10) Council planning

(11)

(12) Courts

(1.3)
(14) Handicapped

(15)

(19)

(20)

(21) Vocationà1 rehab'n

(22) Youth service

(23) Private practice

(24) Other (Please specify.) 
32. What was the setting of your second year of field instruction? Enter the most appropriate numbe from $q .31$.

33. How much full time work experience, paid and volunteer, did you have in social work or human services prior to entering the School of Social Work? Number of years

34. What was your age upon receiving the MSW?

$\begin{array}{ll}\text { (01) } & \text { Under } 24 \\ -(02) & 24-26 \\ -(03) & 27-29\end{array}$

35. What is your sex?

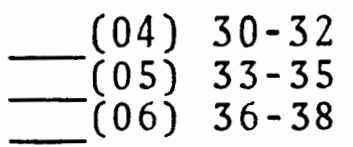

(01) Female
(07) $39-41$

(08) Over 41

36. What is your current marital status?

(01) Married

(02) Single
(03) Divorced/separated

(04) Widowed

37. How many children do you have and what are their ages?
(1)
(2)
$\overline{\mathrm{age}}$
age
(3) $\overline{\mathrm{age}}$
(4)
(5) $\overline{\mathrm{age}}$
(6) $\overline{\text { age }}$

38. What is your present age?

years

39. What is your race and/or ethnicity? (Check as many as are appropriate.)
(01) Asian American
() 2) Black
(03) Chicano
- (04) Native American

(02) Male

40. To which professional organizations do you currently belong?

(Check as many as are appropriate.)

(01) National Association of Social Workers

(02) National Association of Black Social Workers

(03) American Orthopsychiatric Association

(05) Puerto Rican

(06) White

(06) Other (Please specify.)

(04) National Conference of Social Welfare

(05) Child Welfare League of America

(06) American Public Welfare Association

(07) Council of Social Work Education

(08) Other (Please specify.)

(09) None 
Please complete the following questions about your current job performance, being as objective as possible. If you are NOT. currently employed in social work but have been in the past, please skip to q. 51. If you have NEVER been in the social work field, please skip to 9.60 .

41. Using a typical or average MSW with your level of experience as a basis for comparision, please check the box which you think is appropriate concerning your current job performance as a social worker.

(01) Knowledge of theory

(02) Skill in applying theory to practice

(03) Skill in use of supervision and/or consultation

(04) Skill in functioning as a supervisor and/or consultant

(05) Skill in realistically assessing changes needed in agency

(06) Skill in assessing realistically own strengths and areas needing strengthening

(07) Skill in problems assessment

(08) Skill in goal attainment

(09) Skill in using resources (community agencies, colleagues, volunteers, etc.)

(10) Enthusiasm displayed for job

(11) Reliability meeting administrative requirements of job (recording, attending meetings, etc.)

(12) Overall effectiveness in performance

(13) Skill in working with other staff members

(14) Skill in relating to different types of people

(15) Productivity

(16) Skill in adapting to new situations

(17) Openness to change, new ideas, etc. 
42. If you are engaged in direct service, please use the appropriate number to indicate how often you use the following intervention techniques:

1-Never 2-Seldom 3-Sometimes 4-Often 5-Always

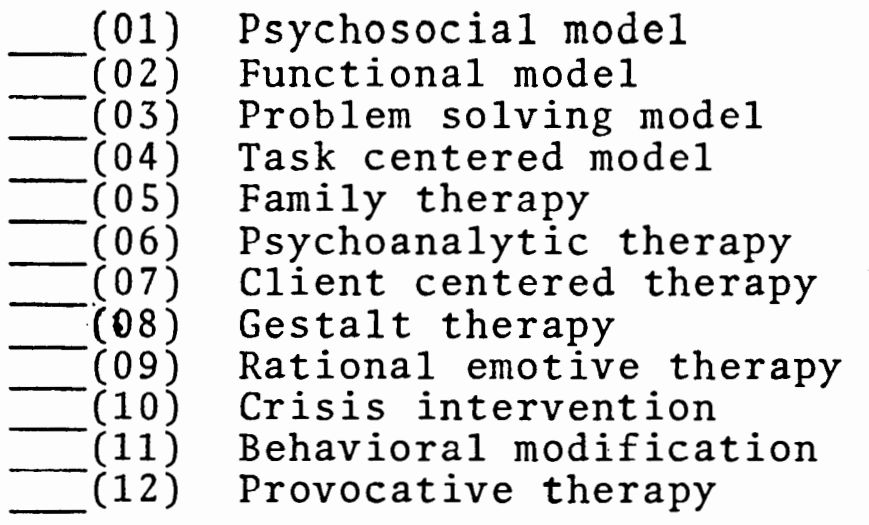

$\begin{array}{ll}\text { (14) } & \text { Radical therapy } \\ -(15) & \text { Adlerian therapy } \\ -(16) & \text { Analytical therapy } \\ -(17) & \text { Existential therapy } \\ -(18) & \text { Encounter therapy } \\ -(19) & \text { Ego psychology approaches } \\ \text { (20) } & \text { Cognitive approaches } \\ \text { (21) } & \text { General systems approaches } \\ \text { (22) } & \text { Role theory approaches } \\ \text { (23) } & \text { Teality therapy } \\ \text { (24) } & \text { Neurolinguistic programming } \\ \text { (25) } & \text { Other (P1ease specify.) }\end{array}$

43. Which intervention technique most deserves additional emphasis in the curriculum? (From list above.)

44. If you are aware of any discriminatory practices in your agency for the following reasons, please indicate below using the codes:

1-rarely 2-sometimes 3-often 4-not aware 5-not applicable IN HIRING IN SERVICE DELIVERY
(01) Sex
(02) Age
(03) Race/ethnicity
(04) Sexual preference
(05) Religion
(06) Income status
(07) Handicapped status
(08) Political ideology

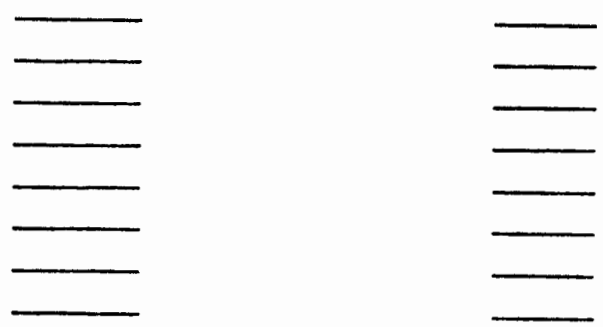

45. If you have personally experienced discriminatory treatment in your agency due to the following reasons, please indicate below using codes:
1-rarely
2-sometimes
3-often
4-not applicab1e

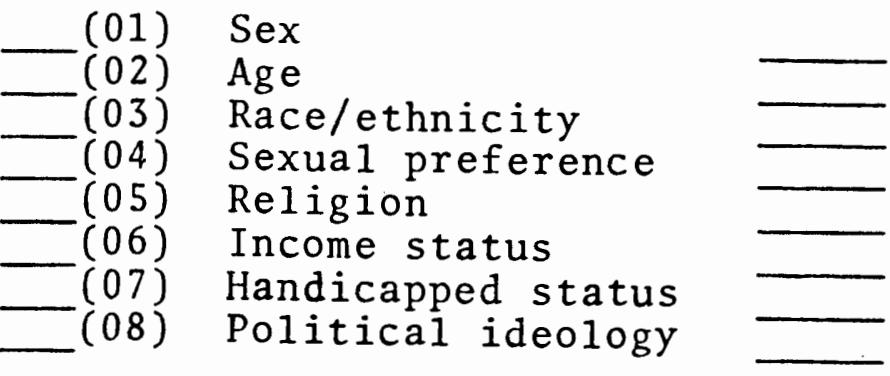


Questions 46-50 ask you about your job. Please indicate in the appropriate box the answer you feel best fits.

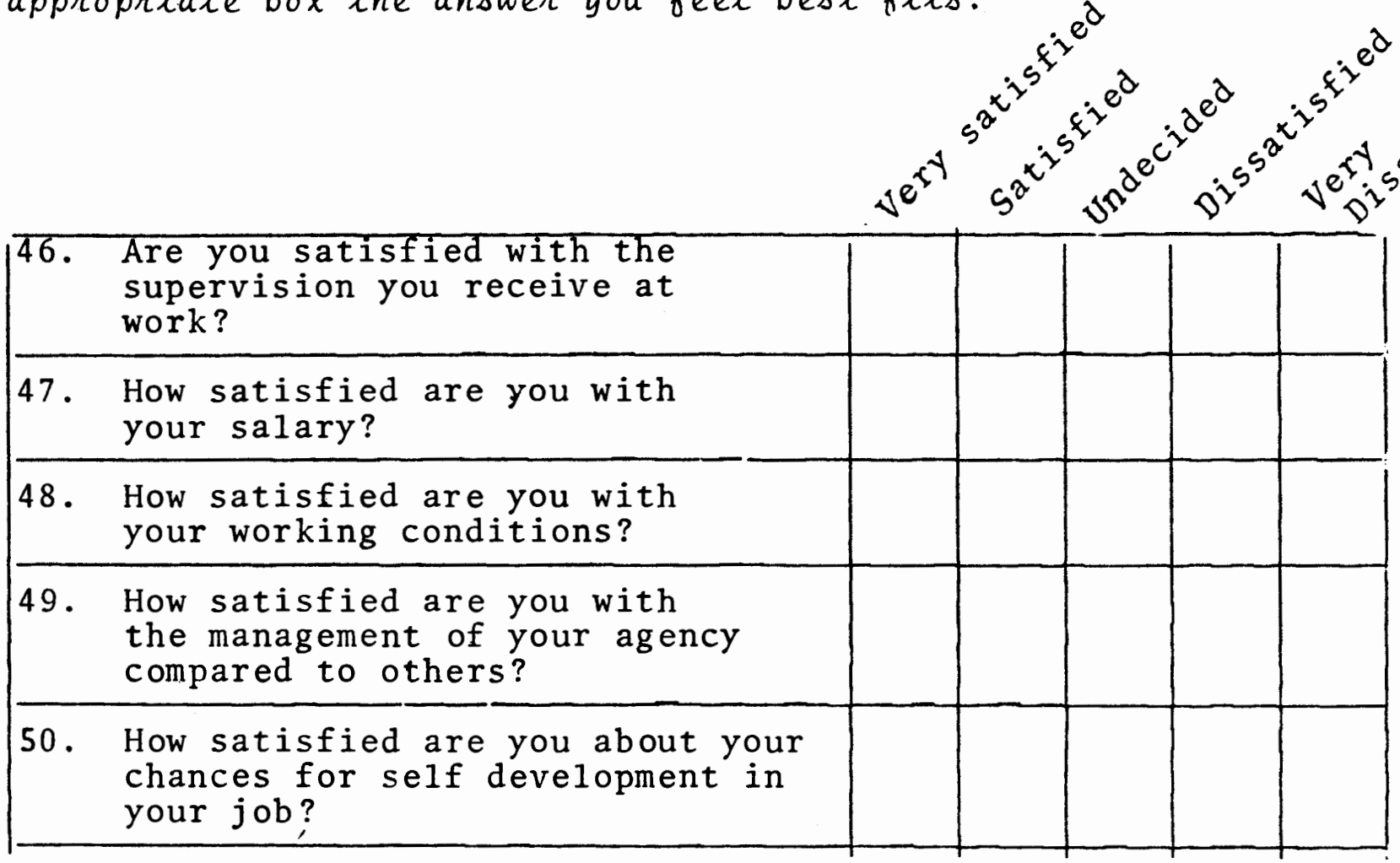

Please respond to questions $51-55$ using as a reference your most recent social work position. Use the following codes:

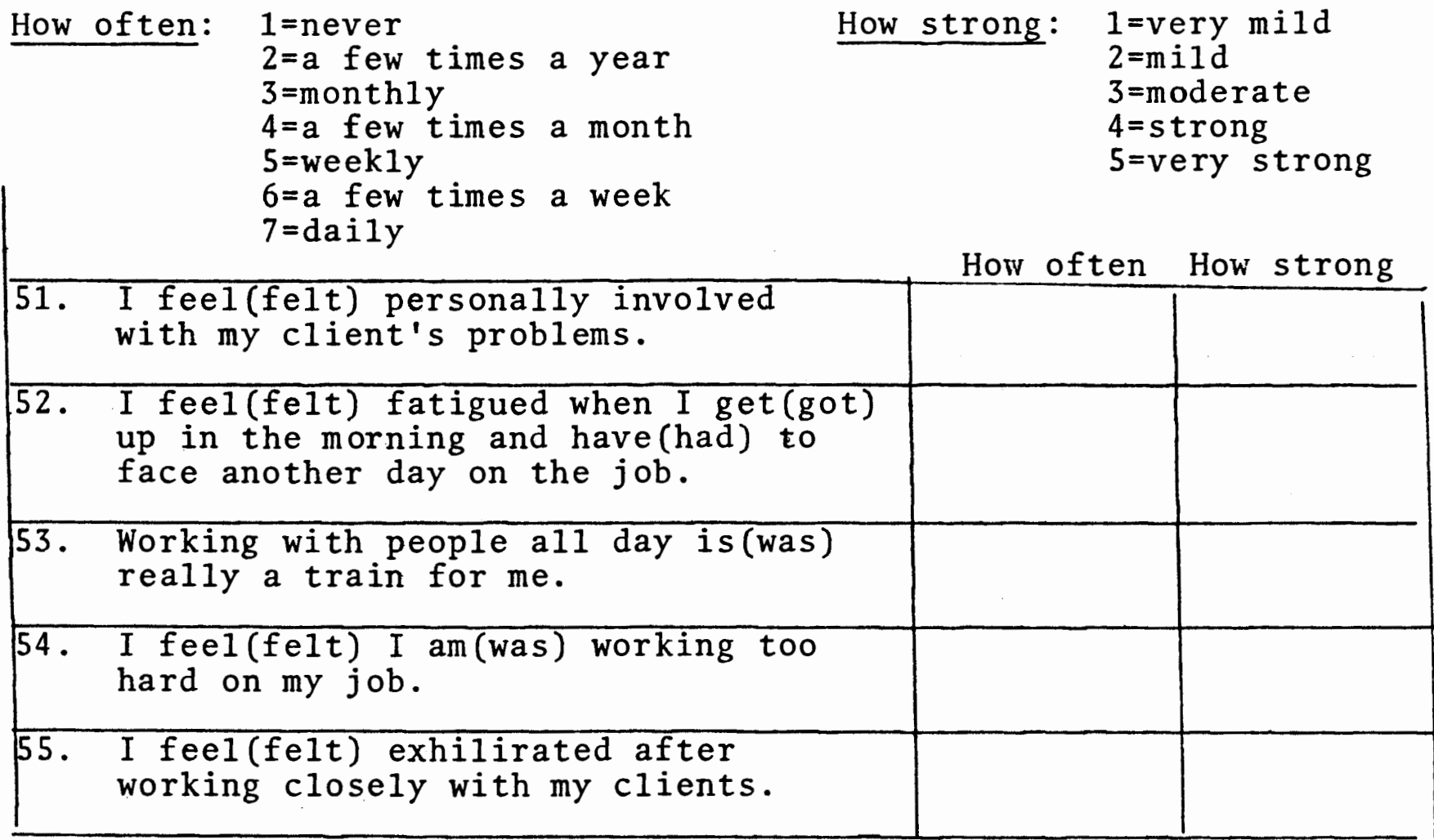


The following questions $(56-59)$ deal with some specific populations with which you may have worked.

Choose from the following list the three categories best describing the client population with which you have the most contact. Using your three choices, answer questions 56-59 (below).'. Use the following codes:

$1=$ never

$$
2=\operatorname{se} 1 \mathrm{dom}
$$$$
3=\text { s ometimes }
$$$$
4=0 f t e n
$$$$
5=a 1 \text { ways }
$$

(1) Substance abuse

(2) Adolescents (12-18 yrs)

(2) Racial/ethnic minorities (Please list specifically)

(3) Sexual minorities

(4) Aged

(5) Low income

(6) Youth $(0-11$ yrs $)$

(7) - Handicapped-physical

(8) Handicapped-emotional

(9) Other

Your choices:

$$
\text { (Please list specifically.) }
$$

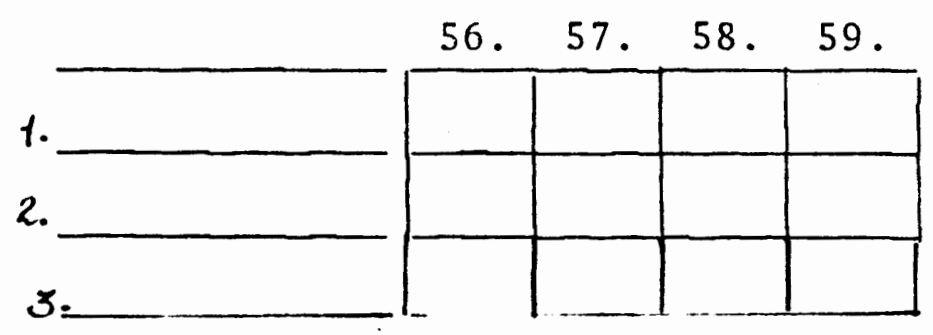

56. How often in your job situation, do(di) you work with problems representing these categories?

57. How often did you find your social work classes prepared you to work effective1y in these areas?

58. Rank the amount of contact you have with people belonging to these groups in your social life.

59. Rank the amount of contact you have with people belonging to these groups in your neighborhood. 
Please indicate your responses to the following questions by chec-ing the appropriate box.
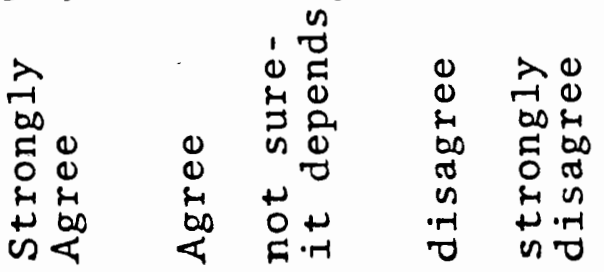
60. Society ought to take some of the responsibility for an individual's problems, hence the need for a social welfare system.

61. Welfare benefits ought to be provided to anyone in need, but those benefits should not exceed the amount one could earn at a minimum wage.

62. In-kind services, such as food stamps and public housing, ought to be abolished to the greatest extent possible in favor of cash grants.

63. A legitimate goal of welfare policy ought to be some redistribution of income.

64. Redistribution policy ought to include provisions for an adequate guaranteed income.

65. Ideally, redistribution would lead to major structural changes in American society, and toward a more socialist orientation.

This is your forum. Any comment you wish to make about the questionnaire, your employment experience, the curriculum at the PSU School of Social work, or any topic at all is welcome. 